\title{
Multiscale Static Analysis of Notched and Un-notched Laminates using the Generalized Method of Cells
}

\author{
B. Stier ${ }^{1}$, P. Naghipour ${ }^{2}$, E. J. Pineda ${ }^{3}$, L. Hansen ${ }^{4}$, S. M. Arnold ${ }^{3}$, B.A. Bednarcyk ${ }^{3}$, A. M. Waas ${ }^{4}$ \\ 1) Institute of Applied Mechanics, RWTH Aachen University, Aachen, Germany \\ 2) Ohio Aerospace Institute, Cleveland, $\mathrm{OH}, 44142$ \\ 3) NASA Glenn Research Center, Cleveland, $\mathrm{OH}, 44135$ \\ 4) University of Michigan, Ann Arbor, MI, 48109
}

\begin{abstract}
The generalized method of cells (GMC) is demonstrated to be a viable micromechanics tool for predicting the deformation and failure response of laminated composites with and without notches subjected to tensile and compressive static loading. Given the axial [0], transverse [90] and shear [+45/45] response of a carbon/epoxy (IM7/977-3) system, the un-notched and notched behavior of three multidirectional layups is predicted under both tensile and compressive static loading. Matrix nonlinearity is modeled in two ways. The first assumes all nonlinearity is due to anisotropic progressive damage of the matrix only; which is modeled using the multiaxial mixed mode continuum damage model (MMCDM) within GMC. The second utilizes matrix plasticity coupled with brittle final failure based on the maximum principle strain criteria to account for matrix nonlinearity and failure within the FEAMAC multiscale framework. GMC/MMCDM and FEAMAC/plasticity incorporate brittle strain and stress based failure criteria for the fiber. Upon satisfaction of this criterion, the fiber properties are immediately reduced to a nominal value. The constitutive response for each constituent (fiber/matrix) is characterized using a combination of vendor data and the axial, transverse and shear response of unnotched laminates. Then, the capability of the multiscale methodology is assessed, by performing blind predictions of the notched and un-notched effective multidirectional IM7/977-3 composite laminates response under tensile and compressive loading. Although tabulated data for all laminates are presented here, only detailed results (i.e., stress-strain curves as well as damage evolution states at various ratios of strain to failure) for a single laminate $\left([+60 / 0 /-60]_{3 s}\right)$ are given.
\end{abstract}

\section{Introduction}

Utilizing micromechanics to capture the progressive damage of carbon fiber reinforced polymer (CFRP) composites is of great importance, as most first-ply failure criteria remain insufficient where significant nonlinearity occurs before final failure [1]. Micromechanics enables one to account explicitly for variations in constituent material properties as well as microstructural effects, such as fiber volume content, fiber packing and orientation, making it a thorough analysis tool for prediction of failure in composites. Moreover, interactive effects between the constituents in the composites are accounted for automatically, rather than through the postulation of an anisotropic continuum damage model.

The generalized method of cells (GMC), first developed by Paley and Aboudi et al. [2] and subsequently enhanced (see ref. [3]), is analytical in nature, and its formulation involves application of several governing conditions in an average sense. It provides the local fields in composite materials, allowing incorporation of any nonlinear constitutive models (both deformation and damage). Within the context of GMC, the microstructure of a periodic material is represented by a rectangular repeating unit cell $(R \cup C)$ consisting of an arbitrary number of rectangular subcells, each of which may be a distinct material (Figure 1). Displacement and traction continuity is enforced in an average, or integral sense at 
each of the subcell interfaces and the periodic boundaries of the RUC. These continuity conditions are used to formulate a strain concentration matrix, which gives all the local subcell strains in terms of the global, average, applied strains. The local subcell stresses can then be calculated using the local constitutive law and the local subcell strains. Finally the overall RUC stiffness is obtained utilizing the local constitutive law and the strain concentration matrix averaged over the RUC dimensions. Various elastic and nonlinear (time-independent plasticity, viscoplasticity, damage) constitutive models available in the MAC/GMC software package, developed by NASA Glenn, facilitate modeling the complex behavior of a composite [3]. Note that, due to the semi-analytical formulation of GMC, fully non-linear solutions (including strain softening) can be efficiently obtained, i.e., on the order seconds. The detailed methodology of GMC and its formulation embedded within classical laminate theory (CLT) is described thoroughly in Refs [2-3].

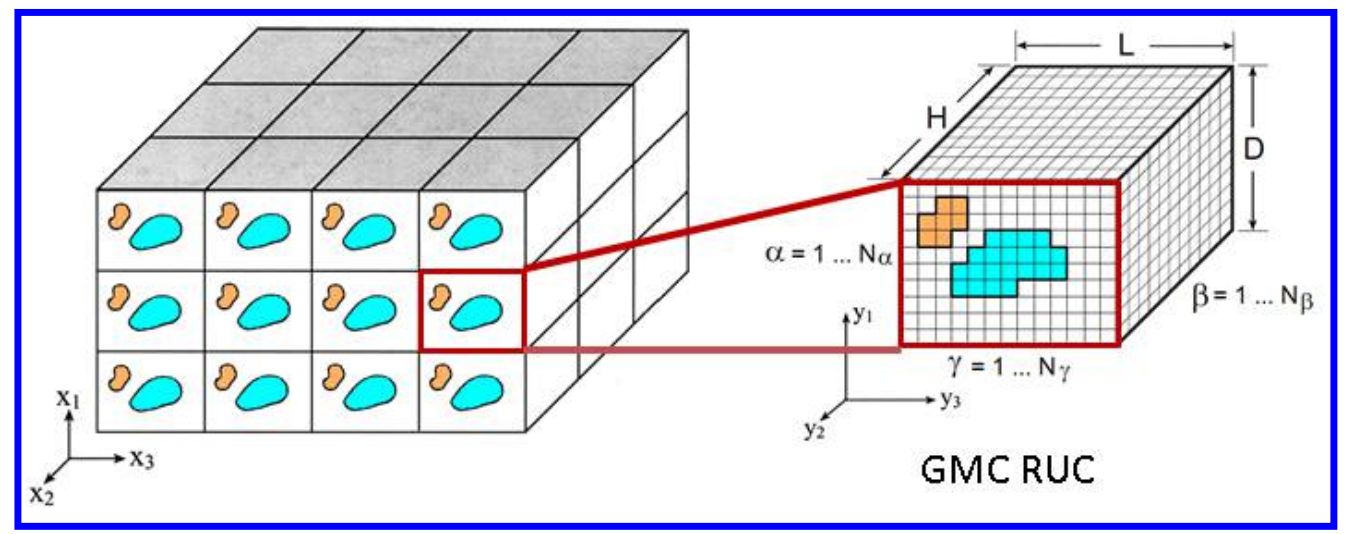

Figure 1: Composite with repeating microstructure and arbitrary constituents.

The multiaxial mixed mode damage model (MMCDM) was initially developed by Bednarcyk et al. [4] within the context of micromechanics. It accounts for the multiaxiality and progressive nature of damage within the constituent materials via anisotropic stiffness reduction based on stress-strain curves for the constituent materials. Final tensile, shear and compression failure criteria are introduced based on the mode-specific strain energy release rates, and a total compressive dissipated strain energy criterion, respectively. Previous results by Bednarcyk et al. [4] and Pineda et al. [5] illustrate the flexibility of the MMCDM to capture the vastly different character of the monolithic (neat) resin matrix and various multidirectional composites in response to far-field loading. It is noted that the main thesis of the MMCDM model is that nonlinearity in polymer matrices within fiber composite laminae are dictated by microcracking, which is the major source of nonlinearity. Consequently, the unloading stiffness is reduced compared to the loading stiffness (unlike in metal plasticity) and closely related to observed and measured experimental responses (see for example, tests by Sicking [6], Schapery and Sicking [7] and Lamborn and Schapery [8]).

The semi-analytical formulation of GMC and its implementation into MAC/GMC offers incredible computational efficiency to obtain the response (e.g., effective properties, global and local (constituent) stress and strain fields) of a volume element of material, yet it is not robust enough to model structural details (i.e., complex geometries, cut-outs, etc.). As such, GMC is ideal for implementation within a multiscale framework, wherein the higher (structural) scale is modeled using the finite element method (FEM). FEAMAC is a synergistic multiscale framework, also developed by NASA Glenn, which couples the micromechanics directly to the FEM and is capable of modeling advanced composite structures $[9,10]$. FEAMAC offers both accuracy and efficiency, at the constituent (fiber/matrix) level and at the global level of a composite structural analysis. In FEAMAC, the micromechanics model (GMC) is called at the desired 
integration points of the finite element model (Figure 2). Any nonlinearity such as plasticity or damage (e.g. MMCDM) in the fiber/matrix constituents at any point in the structure are thus captured locally. The RUC is homogenized, and the non-linear behavior of the micro-constituents within the structure is manifested in the structural response of the FEM model. More information on FEAMAC and examples of its high fidelity as a multiscale analysis tool is available in Ref [3].

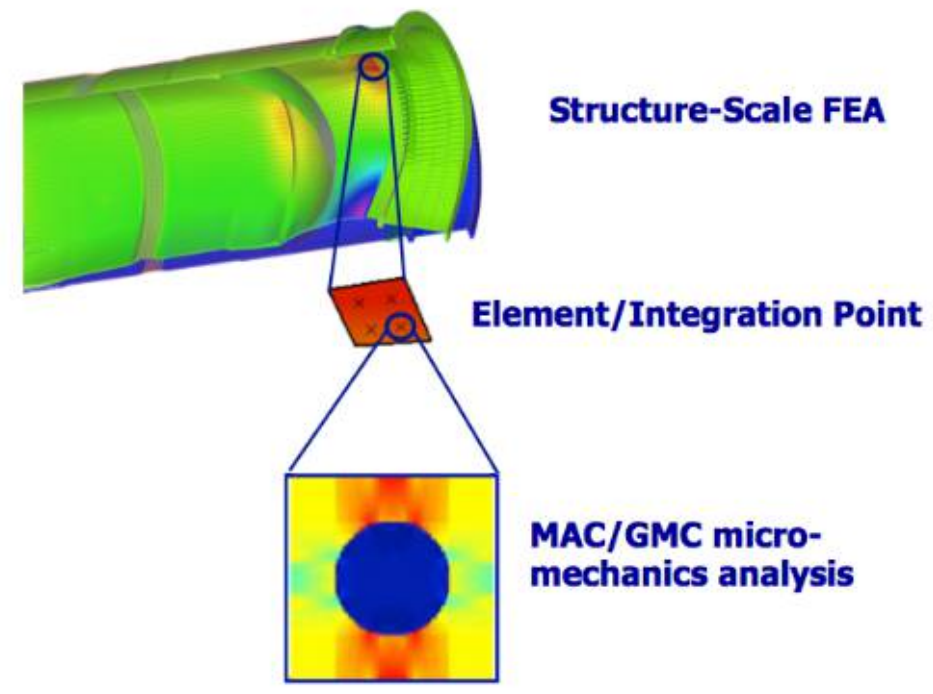

Figure 2: Implementation of the FEAMAC code within the Abaqus built in UMAT framework.

This study was conducted under the support of the Air Force Research Laboratory (AFRL) Tech Scout Project aimed at evaluation of existing progressive damage prediction methods. Blind static and fatigue failure predictions were carried out for three different multidirectional laminates throughout the project timeline. This work demonstrates the application of MAC/GMC, utilizing the MMCDM to model the constitutive response of the GMC matrix subcells, as an ultra-efficient analysis tool to simulate tensile and compressive failure of un-notched, multidirectional IM7/977-3 composite layups. A multiscale framework is required to model structural features, such as notches. Since MMCDM was not fully implemented in the FEAMAC framework at the time of this study, incremental J2 plasticity theory was used in FEAMAC as an alternative to predict the nonlinear response of the matrix subcells notched coupons subjected to tensile and compressive loading [11]. A maximum strain criterion was used to capture failure within the matrix subcells of the FEAMAC/plasticity models. Upon satisfaction of this criterion in any of the matrix subcells, the elastic properties of that subcell were completely diminished. This failure methodology was used for the fiber subcells (which were assumed to exhibit no non-linearity prior to failure) in both the GMC/MMCDM and FEAMAC/plasticity models. For completeness, the unnotched coupons were also modeled using the FEAMAC/plasticity strategy.

The constitutive models used in the blind predictions where characterized and/or calibrated from experimental unnotched coupon data analysis. Subsequently, the models where recalibrated to better correlate to the validation experiments. Tabulated results for all six predictions, along with the calibrations are presented here. However, detailed analysis, including stress-strain curves and damage contours, is only for the $[+60 / 0 /-60]_{3 s}$ laminate. 


\section{Multiaxial Mixed Mode Continuum Damage Model}

The MMCDM, developed by Bednarcyk et al. [4] assumes that damage initiation in each subcell is determined using quadratic definitions of damage strains, a 3-D extension of the strain-based Hashin criterion [4]. ( $X_{\varepsilon}, Y_{\varepsilon}, Z_{\varepsilon}, Q_{\varepsilon}, R_{\varepsilon}, S_{\varepsilon}$, in Equation (1) are strain allowables). Damage is initiated, when any of the specified directional equations (Equation (1)) are greater than or equal to zero.

$$
\begin{aligned}
& \varepsilon_{1}^{D}=\sqrt{\left(\frac{\varepsilon_{11}^{\prime}}{X_{\varepsilon}}\right)^{2}+\left(\frac{\gamma_{13}^{\prime}}{R_{\varepsilon}}\right)^{2}+\left(\frac{\gamma_{12}^{\prime}}{S_{\varepsilon}}\right)^{2}} \\
& \varepsilon_{2}^{D}=\sqrt{\left(\frac{\varepsilon_{22}^{\prime}}{Y_{\varepsilon}}\right)^{2}+\left(\frac{\gamma_{23}^{\prime}}{Q_{\varepsilon}}\right)^{2}+\left(\frac{\gamma_{12}^{\prime}}{S_{\varepsilon}}\right)^{2}} \\
& \varepsilon_{3}^{D}=\sqrt{\left(\frac{\varepsilon_{33}^{\prime}}{Z_{\varepsilon}}\right)^{2}+\left(\frac{\gamma_{23}^{\prime}}{Q_{\varepsilon}}\right)^{2}+\left(\frac{\gamma_{13}^{\prime}}{R_{\varepsilon}}\right)^{2}}
\end{aligned}
$$

Once the damage is initiated, the tangent stiffness, $k_{i}$, of the damage stress versus damage strain curve (Figure 3 ) is used to control the damage evolution law $\left(D_{i}\right.$ is the damage variable)

$$
d D_{i}=\left(1-D_{i}-k_{i}^{\prime}\right) \frac{d \varepsilon_{i}^{D}}{\varepsilon_{i}^{D}}
$$

The normalized tangent stiffness, $k_{i}^{\prime}$, is given in exponential form.

$$
k_{i}^{\prime}=A e^{\frac{-\varepsilon_{i}^{D}}{B}}
$$

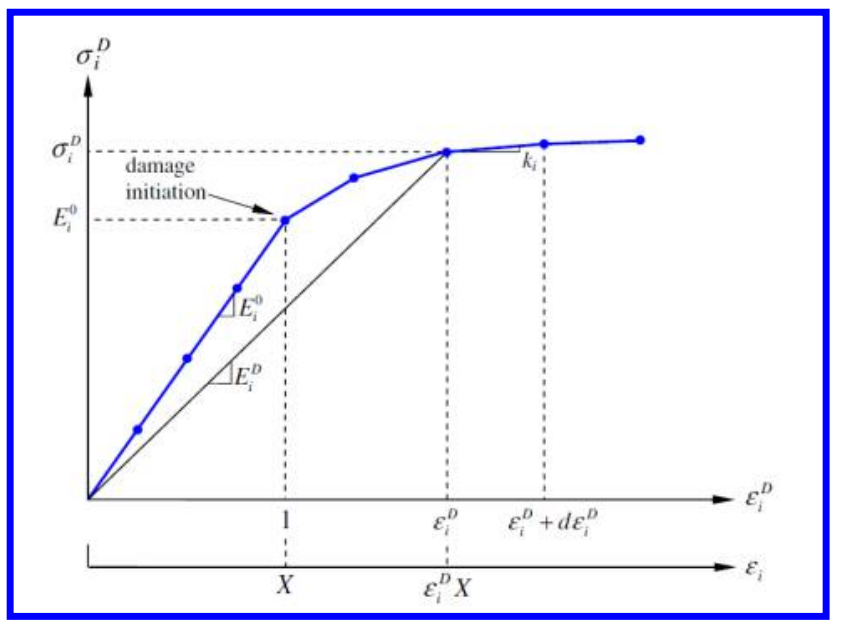

Figure 3. Representation of damage stress versus damage strain curve utilized in the MMCDM to dictated damage evolution.

Once the damage variable is determined, the individual elastic material properties can be degraded (where, $b_{i j}$ are individual damage weighting factors) 


$$
\begin{array}{rlr}
E_{1}=\left(1-b_{11} D_{1}\right) E_{1}^{0} & v_{12}=\left(1-b_{11} D_{1}\right) v_{12}^{0} & G_{12}=\left(1-b_{61} D_{1}-b_{62} D_{2}\right) G_{12}^{0} \\
E_{2}=\left(1-b_{22} D_{2}\right) E_{2}^{0} & v_{13}=\left(1-b_{11} D_{1}\right) v_{13}^{0} & G_{13}=\left(1-b_{51} D_{1}-b_{53} D_{3}\right) G_{13}^{0} \\
E_{3}=\left(1-b_{33} D_{3}\right) E_{3}^{0} & v_{23}=\left(1-b_{22} D_{2}\right) v_{23}^{0} & G_{23}=\left(1-b_{42} D_{2}-b_{43} D_{3}\right) G_{23}^{0}
\end{array}
$$

With the MMCDM a mixed-mode fracture criterion is used to determine the final failure. Upon satisfaction of the ith criterion the $D_{i}$ damage variable is set to value very close to one. Three mixedmode criteria are available: A maximum strain energy release rate, a mixed-mode power law, the Benzeggagh-Kenane (B-K) criterion. However, in this work, a mixed-mode power law criterion is assumed.

$$
\left(\frac{G_{I}^{i}}{G_{I}^{C}}\right)^{\alpha}+\left(\frac{G_{I I}^{i}}{G_{I I}^{C}}\right)^{\alpha}+\left(\frac{G_{I I I}^{i}}{G_{I I I}^{C}}\right)^{\alpha}=1
$$

Here, $G_{M}{ }^{i}$ is the strain energy release rate for a mode $M$ crack perpendicular to the $i$-direction, and $G_{M}{ }^{C}$ is the mode $M$ fracture toughness where $M=I$, II, or III (Figure 4).

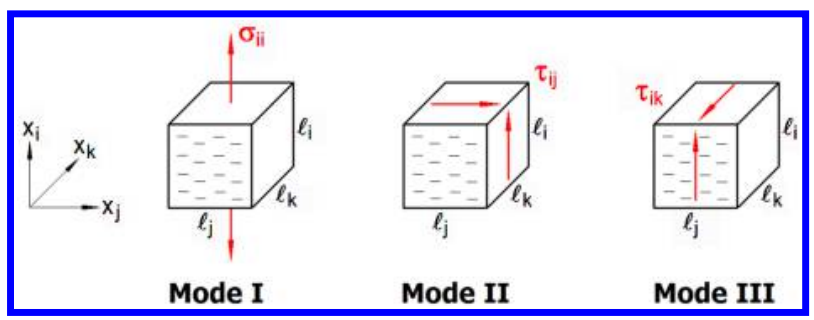

Figure 4. Three fracture modes in the $x$-coordinate frame

It is also assumed that cracks cannot grow under compression. So, for a normal compressive load, a maximum strain energy criterion is used for final failure $\left(W_{s}^{c}=\right.$ critical strain energy), which is determined from increments of the mode-specific strain energy release rates $\left(W_{l}{ }^{i}, W_{I I}{ }^{i}, W_{I I}{ }^{i}\right)$ over the RUC volume. (Equation 6).

$$
W_{I}^{i}+W_{I I}^{i}+W_{I}^{i}=W_{s}^{C}
$$

\section{Characterization and Calibration}

\subsection{MMCDM}

Provided unnotched [0], [90], and $[ \pm 45]_{4 s}$ coupon experimental data were used to calibrate the MMCDM model within MAC/GMC. The elastic properties of fiber and matrix (Table 1) were obtained from vendor data or were partially backed out from elastic lamina properties measured for IM7/977-3. The 7x7, doubly-periodic, square packed RUC (shown in Figure 5a, which represents continuous reinforcement was used for analyzing the composite material. The matrix (represented by green subcells) was assumed isotropic with a Young's modulus $E_{m}$ and a Poisson's ratio $v_{m}$, and the fiber (shown with blue subcells) was assumed transversely isotropic, where $E_{f 11}$ is the longitudinal modulus, $E_{f 22}$ is the 
transverse modulus, $v_{\mathrm{f} 12}$ and $G_{\mathrm{f} 12}$ is the axial shear modulus. A volume fraction of $65 \%$ was used. CLT (Figure $5 b$ ) within MAC/GMC was used to model all un-notched laminates, including the characterization coupons, wherein the RUC represented in Figure 5a provides the constitutive response of the integration points within each layer.

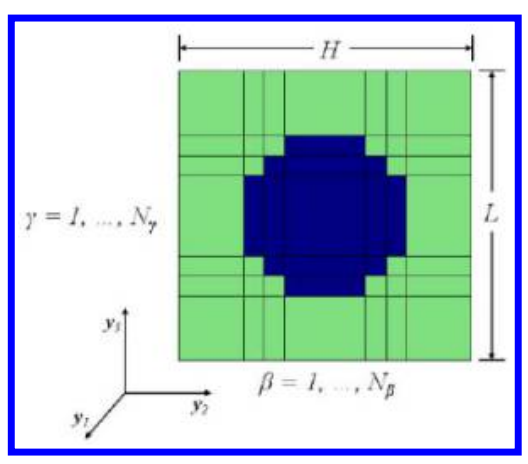

Figure 5a: Square-packed 7x7 RUC subcell architecture. Blue subcells=Fiber, green subcells= matrix

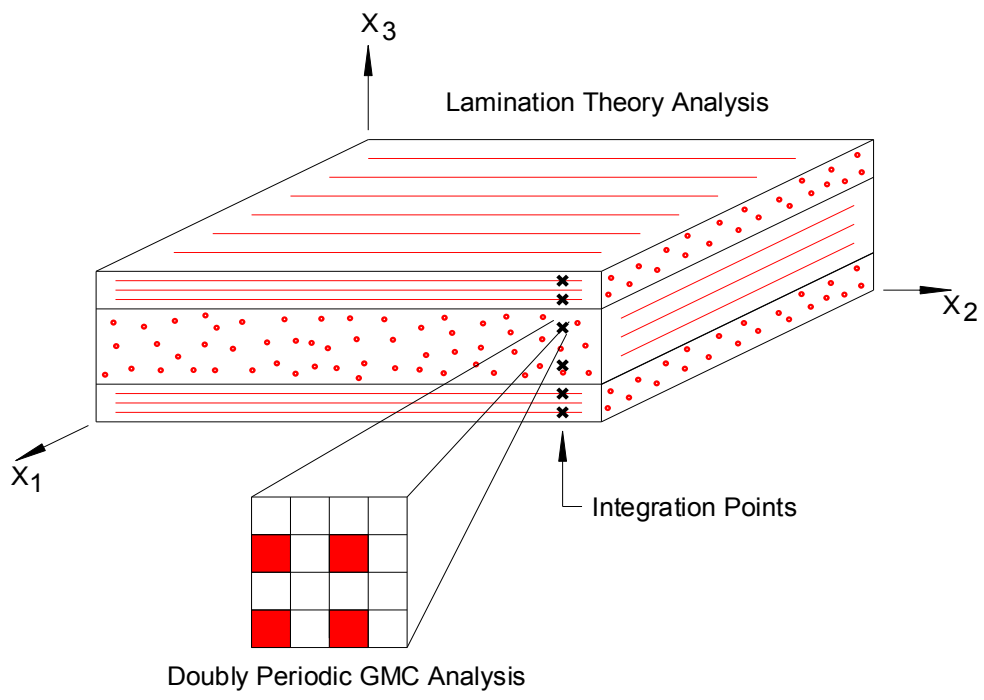

Figure 5b. CLT within MAC/GMC.

Data from three uniaxial coupon tests, $[0]_{8}$ (longitudinal tension), $[0]_{16}$ (longitudinal compression), $[90]_{16}$ (transverse tension), $[90]_{24}$ (transverse compression), and $[ \pm 45]_{45}($ shear), provided by AFRL as a part of the Tech Scout Project [11], were used to calibrate the inputs for the MMCDM model within MAC/GMC. All of the parameters calibrated for the MMCDM model, together with abovementioned constituent properties, are summarized in Table 1. For fiber failure, the subcell elimination method was used. A maximum normal stresses criterion, with different critical strains in tension and compression based on $0^{\circ}$ tension and compression tests $\left(\varepsilon_{\text {fiber }}^{\text {ult }}\right)$, was employed. With the subcell elimination method, the elastic properties of a subcell are immediately reduced to a near-zero value upon satisfaction of a failure criterion. The detailed definition of the MMCDM properties listed in Table 1 can be found in Section 2. 


\begin{tabular}{|c|c|c|}
\hline $\mathrm{E}_{\mathrm{f} 11}=276 \mathrm{GPa}$ (Tension)/ $215 \mathrm{GPa}$ (Compression) & $X_{\varepsilon}^{T}=0.012$ & $\varepsilon_{\text {fiber }}^{\text {ult }}$ (tension $)=0.0161$ \\
\hline $\mathrm{E}_{\mathrm{f} 22}=16 \mathrm{GPa}$ & $S_{\varepsilon}=0.0253$ & $\varepsilon_{\text {fiber }}^{\text {ult }}($ compression $)=0.0098$ \\
\hline$v_{\mathrm{f} 12}=0.31$ & $X_{\varepsilon}^{C}=0.0337$ & $\mathrm{G}_{1}^{\mathrm{C}}=6 \mathrm{~J} / \mathrm{m} 2$ \\
\hline$v_{f 23}=0.28$ & $A^{\top}=1, B^{\top}=3.25$ & $\mathrm{G}_{\|}{ }^{\mathrm{C}}=\mathrm{G}_{\| I}{ }^{\mathrm{C}}=250 \mathrm{e} 3 \mathrm{~J} / \mathrm{m} 2$ \\
\hline$G_{\mathrm{f} 12}=15 \mathrm{GPa}$ & $A^{C}=1, B^{C}=2.5$ & Wsc $=5.55$ e- $6 \mathrm{~J} / \mathrm{m} 2$ \\
\hline $\mathrm{E}_{\mathrm{m}}=3.5 \mathrm{GPa}$ & $\mathrm{b}_{22}{ }^{\top}=2, \mathrm{~b}_{\mathrm{ii}}{ }^{\top}=1\left(\mathrm{i}^{\neq} \mathbf{2}\right)$ & \\
\hline$v_{m}=0.35$ & $b_{i i}{ }^{C}=1, b_{4 i}=b_{5 i}=b_{6 i}=0.5$ & \\
\hline
\end{tabular}

Table 1: Constituent (fiber/matrix) properties and MMCDM parameters

\subsection{Plasticity}

Figure 6 shows how the micromechanics-based GMC was used in conjunction with the Abaqus [12] FEM software package within the FEAMAC framework: GMC is called at each integration point of the composite ply within the FE model.

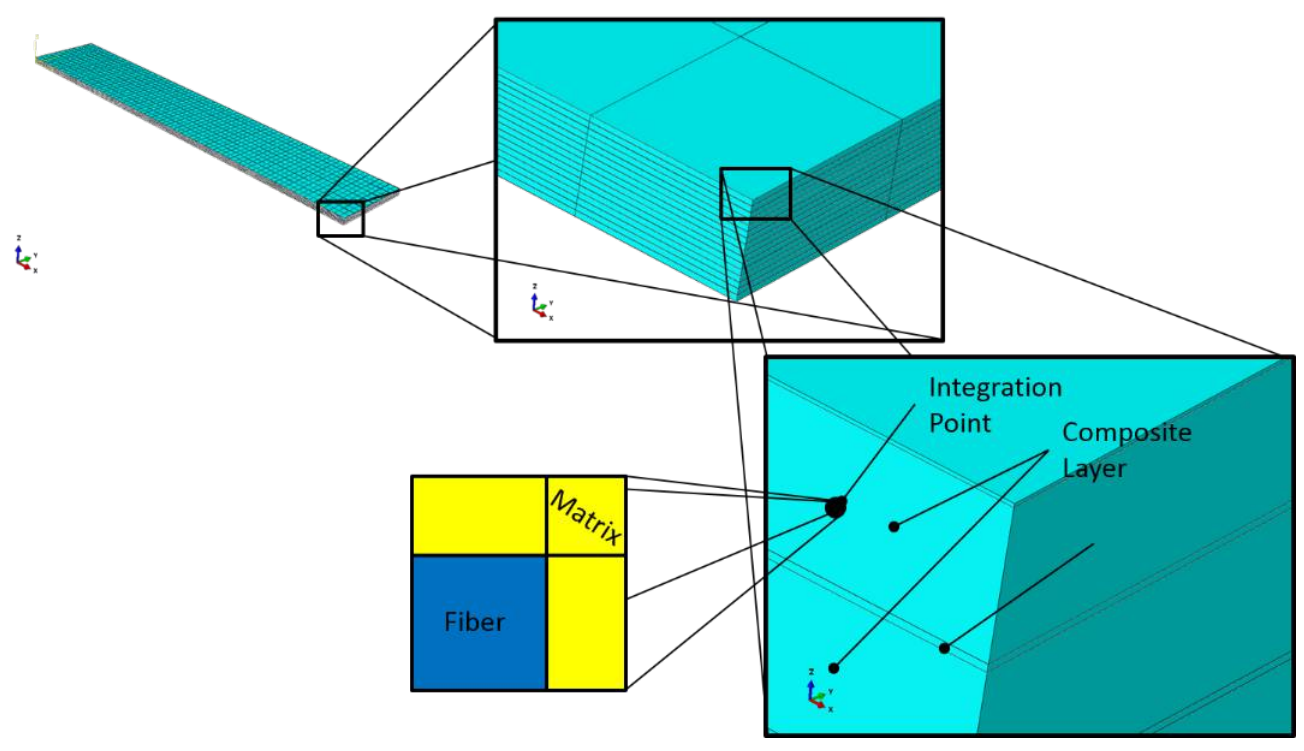

Figure 6: GMC within FEAMAC

A full 3D approach was used, discretizing every layer with single C3D8R (linear 3D) element across the thickness. In Between each layer, a cohesive zone layer was incorporated to account for delamination using $\mathrm{COH} 3 \mathrm{D} 8$ elements. The cohesive layers were assumed to be linear elastic prior to damage initiation, with an assumed strength of $44 \mathrm{MPa}$. After a critical cohesive stress value is reached, interfacial damage starts to evolve based on a mixed mode damage evolution criterion. The fracture toughness values were taken from mode-I and mode-II fracture tests $\left(G_{\mid c} \sim 0.25 \mathrm{~mJ} / \mathrm{mm}^{2}\right.$ and $\left.\mathrm{Gl}_{\mathrm{lc}} \sim 0.75 \mathrm{~mJ} / \mathrm{mm}^{2}\right)$ and were held constant by adjusting the slope of the softening part using the characteristic length. The cohesive layers were modeled as pure matrix continuum layers with $5 \%$ of the nominal ply thickness. Thus, the fiber volume fraction was increased in the effective composite layers accordingly. Displacement boundary conditions were applied at one end of the specimen, whereas the other end was held fixed in the loading direction. Furthermore, boundary conditions at the specimen ends prohibited bending and twisting as well as rigid body movement during the loading step. 
Sectioning of the panels revealed a non-uniform distribution of fibers in the panels, yielding a higher fiber volume fraction near the gripped edges of the panel. This feature was incorporated in the FEAMAC model by utilizing a $67 \%$ fiber volume fraction in the gage section and a $70 \%$ fiber volume fraction near the gripped edges.

Even though matrix nonlinearity is dominated by microcracking the MMCDM was not available within the FEAMAC multiscale framework at the time of the study. Since there was no global unloading in the experiments, incremental $J 2$ plasticity theory was deemed a convenient, alternative approach to capture this nonlinearity. If local unloading is present, a major discrepancy between MMCDM and plasticity would be observed. MMCDM is a secant theory assuming all dissipated energy is utilized to advance microcracks, resulting in stiffness degradation, whereas plasticity theory assumes energy is dissipated through dislocation motion, resulting in permanent plastic strain. In this study, when plasticity is used, the assumption is that microdamage and inelastic material behavior follows the same evolution law as dislocation motion in metals observe.

The same elastic properties for the constituents and critical fiber strains were used in all models. However, the models incorporating plasticity used the same value for the longitudinal modulus of the fiber in tension and in compression $(276 \mathrm{GPa})$. For the plasticity model, data from the $\left[+45^{\circ} /-45^{\circ}\right]_{45}$ was used to characterize the effective nonlinear stress-strain response of the matrix. A tabulated form of this effective stress-strain curve (Figure 7) was used directly in MAC/GMC and FEAMAC to dictate the strain hardening behavior of the matrix subcells.

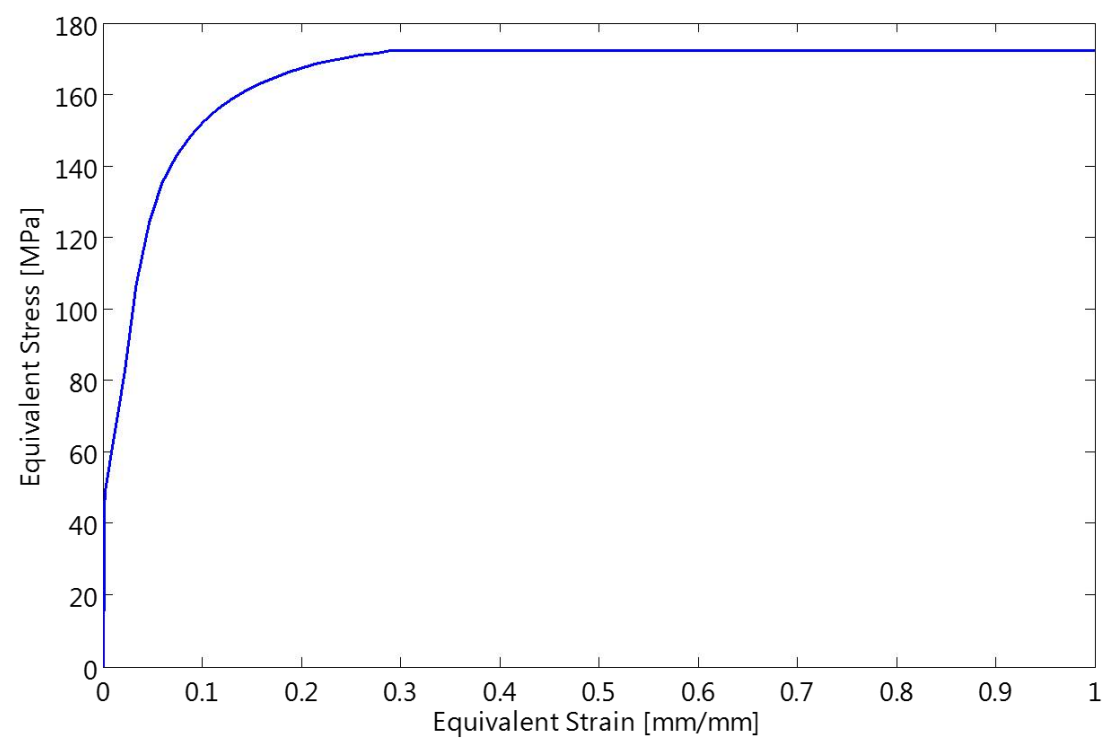

Figure 7: Characterization of the effective nonlinear stress-strain response of the matrix

To capture matrix failure the subcell elimination method was used. A strain-based failure criterion, with different allowables in tension, $\varepsilon^{\text {ult }}{ }_{m}$, and in shear, $v^{\text {ult }}{ }_{m}$, (based on transverse and shear tensile tests, respectively) was employed to mark the end of the local stress-strain curve. Table 2 summarizes the complete list of unique properties used in the models utilizing plasticity theory. 


\begin{tabular}{|l|l|}
\hline $\mathrm{E}_{\mathrm{f} 11}=276 \mathrm{GPa}$ (Tension / Compression) & $\varepsilon^{\text {ult }}{ }_{\text {fiber }}$ (tension) $=0.0161$ \\
\hline $\mathrm{E}_{\mathrm{f} 22}=15 \mathrm{GPa}$ & $\varepsilon^{\text {ult }}$ fiber (compression) $=0.0098$ \\
\hline $\mathrm{V}_{\mathrm{f} 12}=0.28$ & $\mathrm{~V}_{\mathrm{f}}=67 \%$ \\
\hline $\mathrm{V}_{\mathrm{f} 23}=0.19$ & $\varepsilon^{\text {ult }}{ }_{\mathrm{m}}=0.0139$ \\
\hline$G_{\mathrm{f} 12}=15 \mathrm{GPa}$ & $\gamma^{\text {ult }}{ }_{\mathrm{m}}=0.06$ \\
\hline $\mathrm{E}_{\mathrm{m}}=3.2 \mathrm{GPa}$ & $\sigma \mathrm{y}=48.3 \mathrm{MPa}$ \\
\hline $\mathrm{V}_{\mathrm{m}}=0.38$ & \\
\hline
\end{tabular}

Table 2: Matrix properties and plasticity theory parameters

\subsection{Characterization and Calibration Results}

The resulting uniaxial stress strain curves for the above-mentioned $0^{\circ}, 90^{\circ}$ and $+45 /-45^{\circ}$ laminates, using both MMCDM and plasticity within GMC, are presented in Figure 8. Both MMCDM and plasticity were able to correlate very well for all three laminates, especially with MMCDM capturing the highly nonlinear shear and transverse compression behavior.

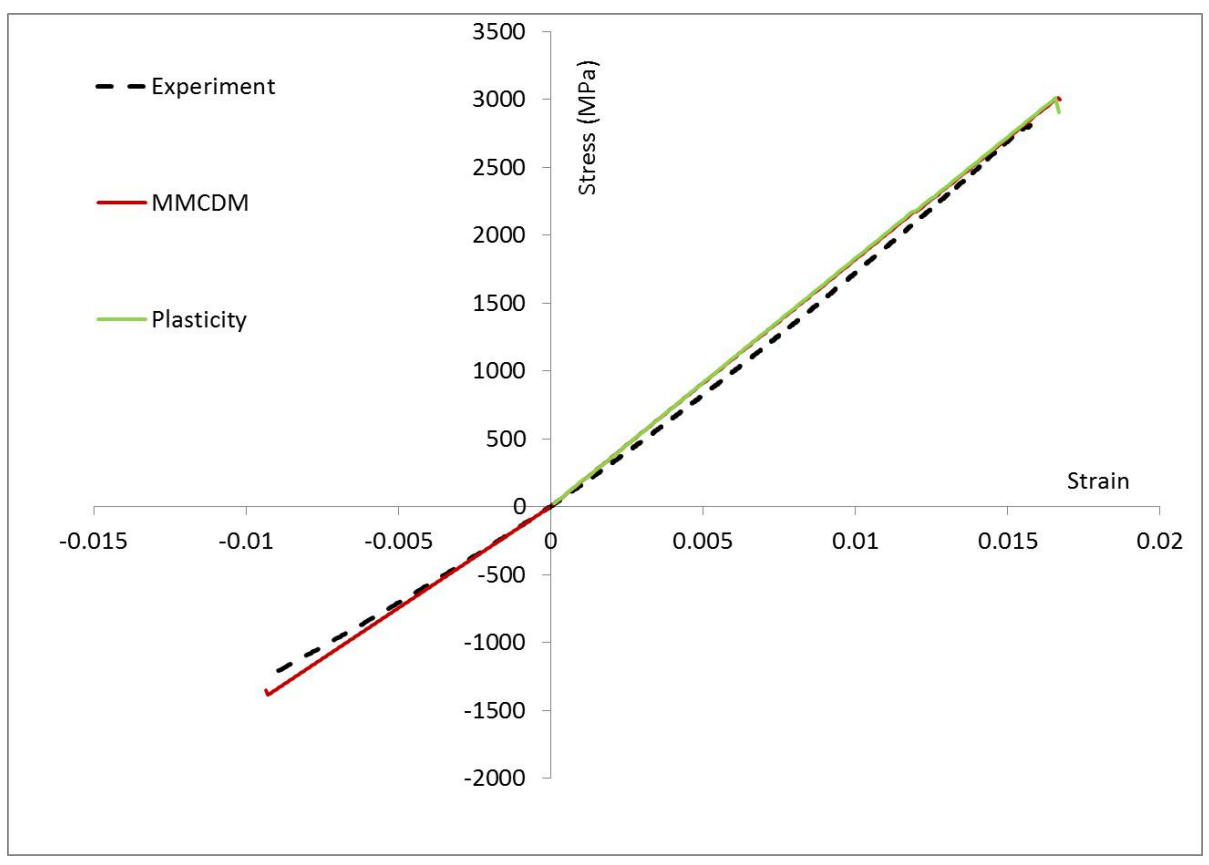

Figure 8a: Uniaxial stress-strain curve: Laminates [0] $]_{8}$ (longitudinal tension), [0] $]_{16}$ (longitudinal compression) MMCDM and plasticity versus experiment 


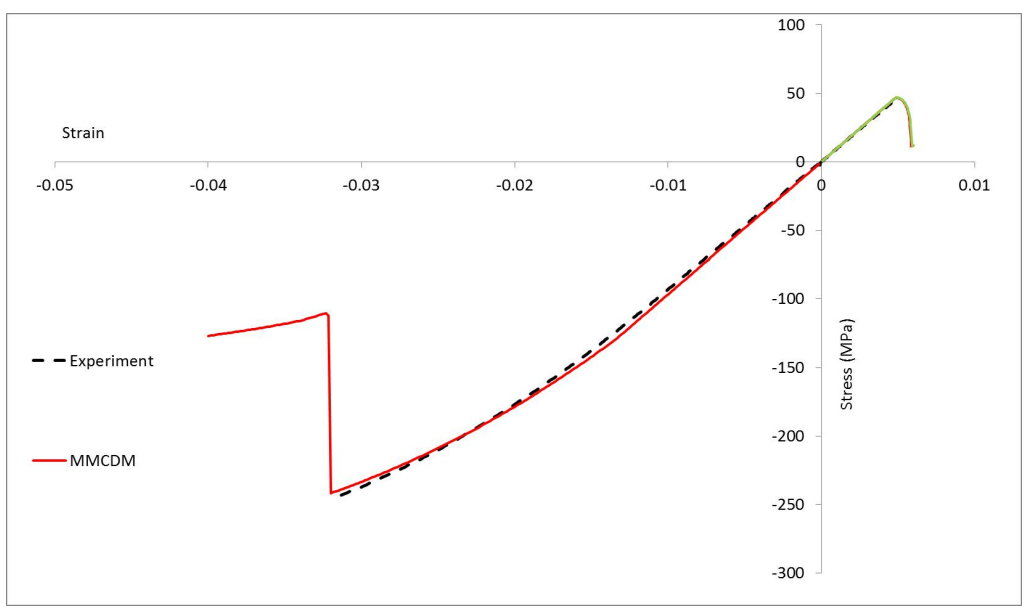

Figure 8b: Uniaxial stress-strain curve: Laminates [90 $]_{16}$ (transverse tension), [90 $]_{24}$ (transverse compression) MMCDM and plasticity versus experiment-transverse response calibrated only with MMCDM)

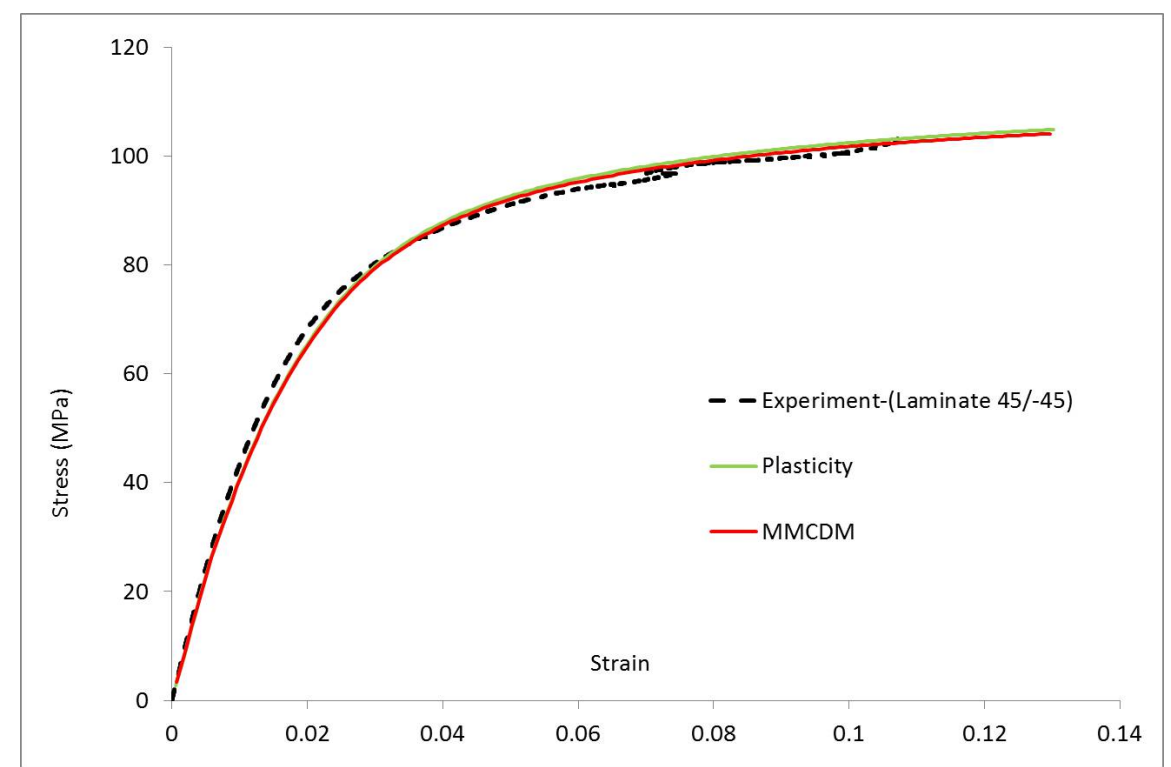

Figure 8c: Uniaxial stress-strain curve: Laminate $[45 /-45]_{4 s}$ MMCDM and plasticity versus experiment

\section{Results}

\subsection{Unnotched Laminate}

The calibrated properties (Table 1 and Table 2) were used to predict the failure response of three different unnotched multidirectional layups (including [+60/0/-60 $]_{3 s}$ ) utilizing MMCDM theory within $\mathrm{MAC} / \mathrm{GMC}$ (microscale) and plasticity within FEAMAC (multiscale). Here, only the obtained stress-strain response (blind predictions for Layup $2\left([+60 / 0 /-60]_{35}\right)$ will be described in detail. However, three pointwise properties, i.e., stiffness, maximum stress and failure strain, are tabulated for all three layups in Section 4.1.3. 


\subsubsection{A) MMCDM: Blind Predictions}

The calibrated properties (Table 1) were used in the MMCDM within MAC/GMC to predict the failure response of the un-notched multidirectional laminates. The experimentally reported stress/strain curve for the $[+60 / 0 /-60]_{3 \text { s }}$ laminate under tension was predicted successfully with $1.99 \%$ error in ultimate strength prediction. However, the initial stiffness was over-predicted by $13.37 \%$ as a result of off-axis plies carrying load after failure in the RUC (Figure 9a). Dashed lines in the figures designate the (90-95)\% upper and lower confidence bounds for all the reported experimental results.

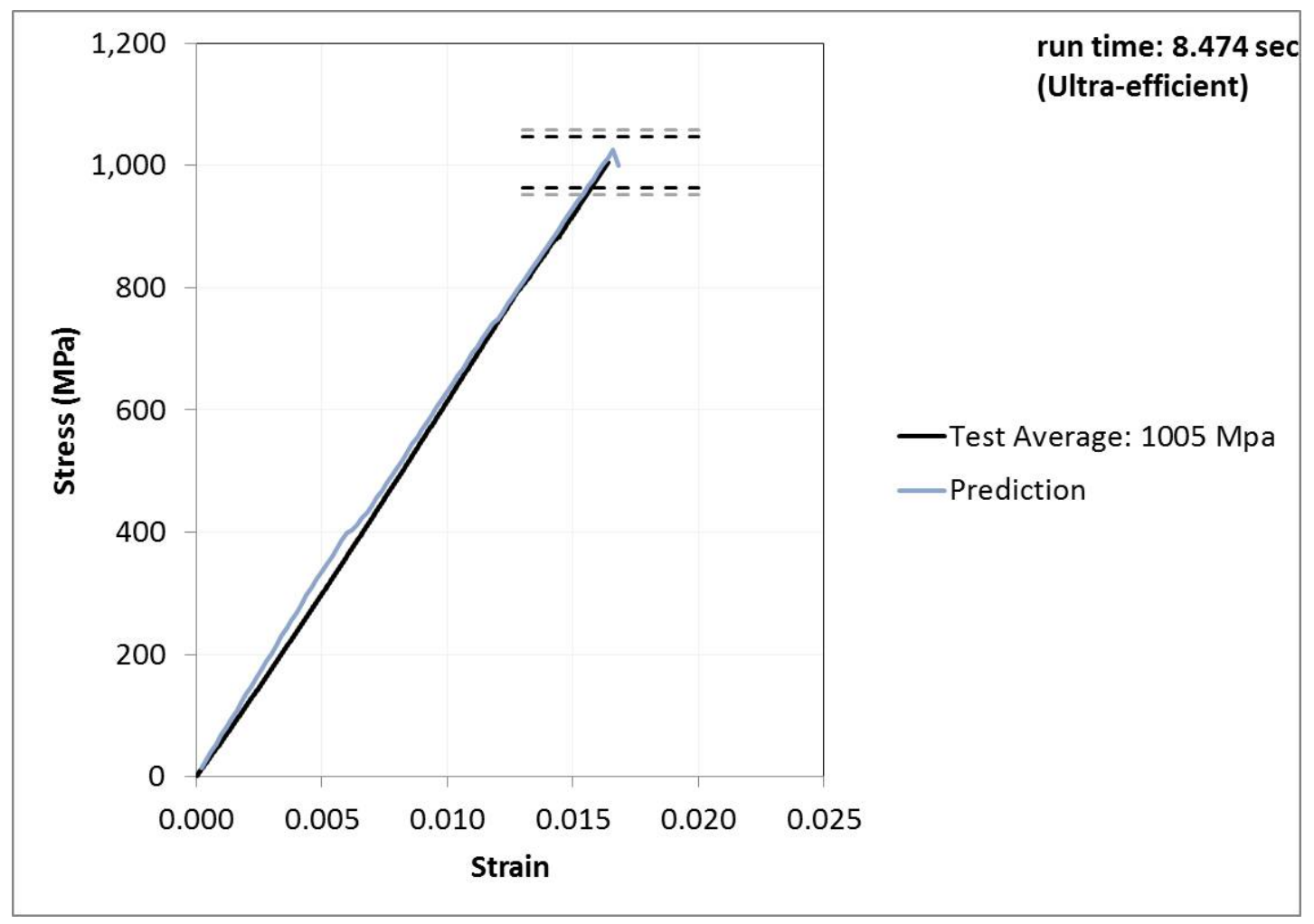

Figure 9a: Stress-Strain prediction for the [60/0/-60]3s unnotched layup (Tension)

Under compression, the strength was under-predicted by $37 \%$, while the stiffness is overpredicted by $11 \%$. This is due to the assumed low value for the $0^{\circ}$ compression strength. The reported initial value by AFRL [11] for the axial compressive strength was $1274 \mathrm{MPa}$, which is much lower compared to available previous experimental results ( $1680 \mathrm{MPa})$ for the same class of materials. AFRL planned to carry out another set of axial compression experiments to address the inconsistency. Meanwhile, the axial compressive strength of the fiber was increased accordingly to improve the results later in the recalibration phase. The observed non-linearity under compression due to kink-banding is also not captured in the initial predictions, which is addressed successfully in the recalibration part (Section 4.1.1 B). 


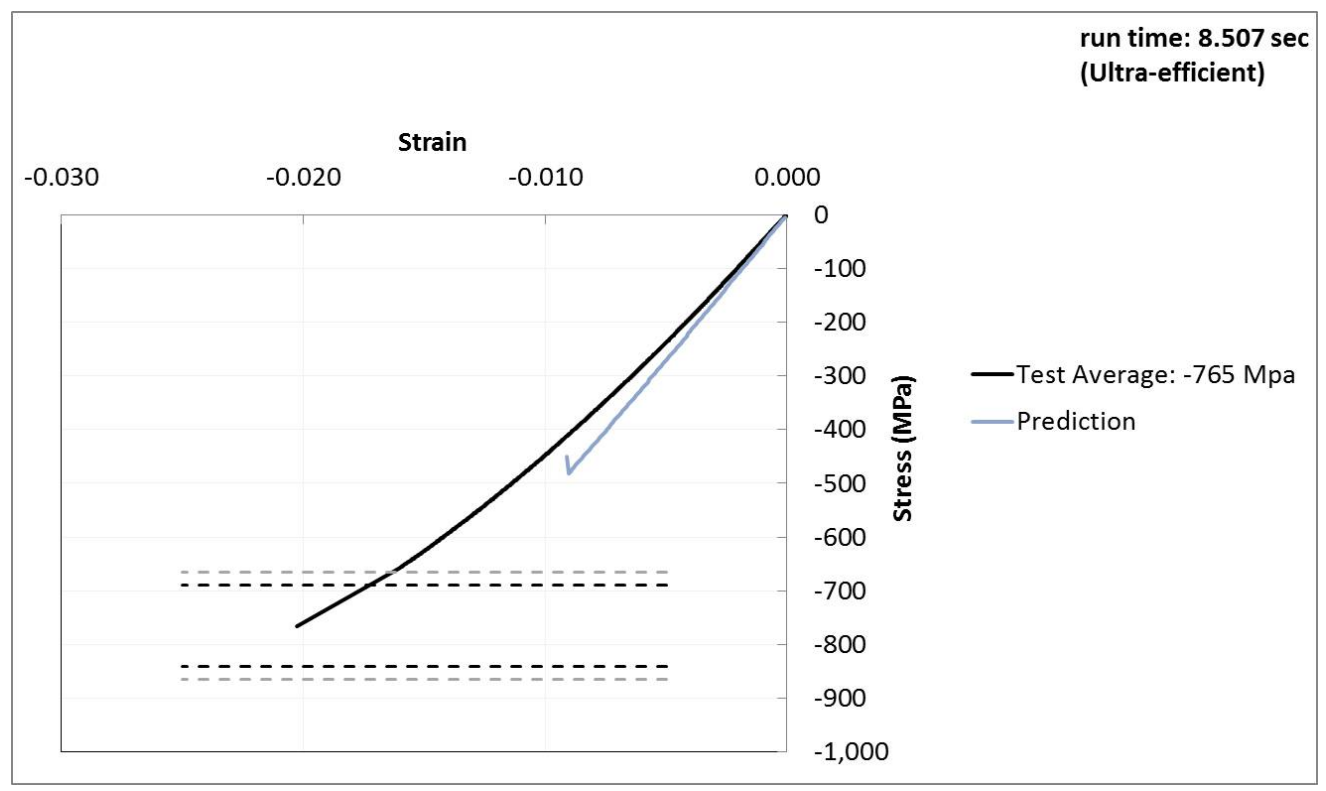

Figure 9b: Stress-Strain prediction for the [60/0/-60]3s unnotched layup (Compression)

\subsubsection{B) MMCDM: Recalibration}

During the recalibration phase, four modifications were made to improve the results obtained using GMC with MMCDM. First, the fiber failure criterion was changed from maximum strain to a "Hashin"-like failure, which incorporated a shear strain component. A shear strain allowable $\left(X_{\text {fiber }}\right.$ (shear) $=0.003$ ) was introduced. Once the damage is initiated, the tangent stiffness of the damage stress versus damage strain curve (see Figure 3 , Section 2 ) is used to control the nonlinear damage evolution law with slope parameters $\left(A_{\text {fiber }}^{\top}, B_{\text {fiber }}^{\top}\right.$ ). This was necessary to eliminate load-carrying capability of offaxis plies when matrix has failed in tension, a deficiency resulting from utilizing CLT. Second, under compression the fiber was modeled using MMCDM to account for axial nonlinearity due to kink-band formation. Furthermore, the compressive strength of the fiber was increased to match the recommended value in the literature [11], and lastly, the longitudinal stiffness of the fiber was decreased accordingly [11]. The parameters used in MMCDM for the recalibration phase are shown in Table 3 (post blind prediction modifications are shown in red).

\begin{tabular}{|c|c|c|}
\hline $\mathrm{E}_{\mathrm{f} 11}=256 \mathrm{GPa}$ (Tension)/215 GPa (Compression) & $X_{\varepsilon}^{T}=0.012$ & $\begin{array}{l}X_{\text {fiber }}(\text { tension })=0.0161 \\
X_{\text {fiber }}(\text { shear })=0.003-- \text { Hashin }\end{array}$ \\
\hline $\mathrm{E}_{\mathrm{f} 22}=16 \mathrm{GPa}$ & $S_{\varepsilon}=0.0253$ & $\mathrm{X}_{\text {fiber }}($ compression $)=0.0075$ \\
\hline$v_{\mathrm{f} 12}=0.31$ & $X_{\varepsilon}^{C}=0.0337$ & $\mathrm{~A}_{\text {fiber }}^{\top}=1, \mathrm{~B}_{\text {fiber }}^{\top}=4.5$ \\
\hline$v_{\mathrm{f} 23}=0.28$ & $A_{m}^{\top}=1, B_{m}^{\top}=3.25$ & $W_{s c}=1.66 e-5 \mathrm{~J} / \mathrm{m} 2$ \\
\hline$G_{\mathrm{f} 12}=15 \mathrm{GPa}$ & $A_{m}^{C}=1, B_{m}^{C}=2.5$ & $\mathrm{G}_{1}^{\mathrm{C}}=6 \mathrm{~J} / \mathrm{m} 2$ \\
\hline $\mathrm{E}_{\mathrm{m}}=3.5 \mathrm{GPa}$ & $b_{22}^{\top}{ }_{2}=2, b_{i i}^{\top}=1\left(i^{\neq 2} 2\right)$ & $\mathrm{G}_{\|}{ }^{\mathrm{C}}=\mathrm{G}_{\| \mid}{ }^{\mathrm{C}}=250$ e $3 \mathrm{~J} / \mathrm{m} 2$ \\
\hline$v_{m}=0.35$ & $b_{i i}{ }^{c}=1, b_{4 i}=b_{5 i}=b_{6 i}=0.5$ & $\mathrm{WsC}_{\mathrm{m}}=5.55 \mathrm{e}-6 \mathrm{~J} / \mathrm{m} 2$ \\
\hline
\end{tabular}

Table 3: Constituent (fiber/matrix) properties and MMCDM parameters (recalibration) 
Figure 10 shows the blind predictions and recalibrated plots together with experimental results for the aforementioned unnotched $[+60 / 0 /-60]_{3 s}$ layup. As shown in Figure 10b, these changes significantly improved the result for the compression case, successfully capturing the observed experimental non-linear response. For tension, the recalibration improved the initial stiffness prediction, however, correlation of the strength prediction with experiments was reduced. The additional compliance predicted during the recalibration is due to the assumed Hashin failure criteria. Despite a small discrepancy for this particular layup, the results for the other two layups were significantly improved, i.e., the relative error in strength prediction was reduced from $72 \%$ to $0.4 \%$ for layup 3 , and from $20 \%$ to $10 \%$ for Layup 1 . (See Table 5 - Section $4-1-3$ for details). It should be noted that the maximum runtime for the MAC/GMC MMCDM simulations was 8.5 seconds using a single CPU.

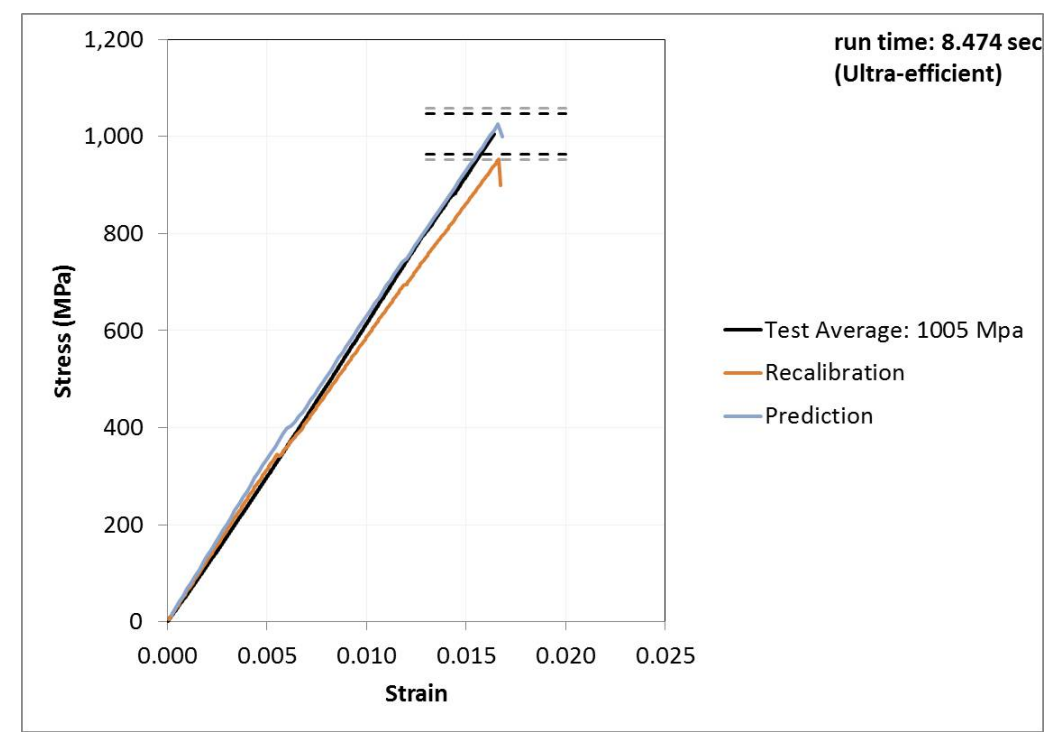

Figure 10a: Stress-Strain prediction and recalibration for the [60/0/-60]3s unnotched layup (Tension)

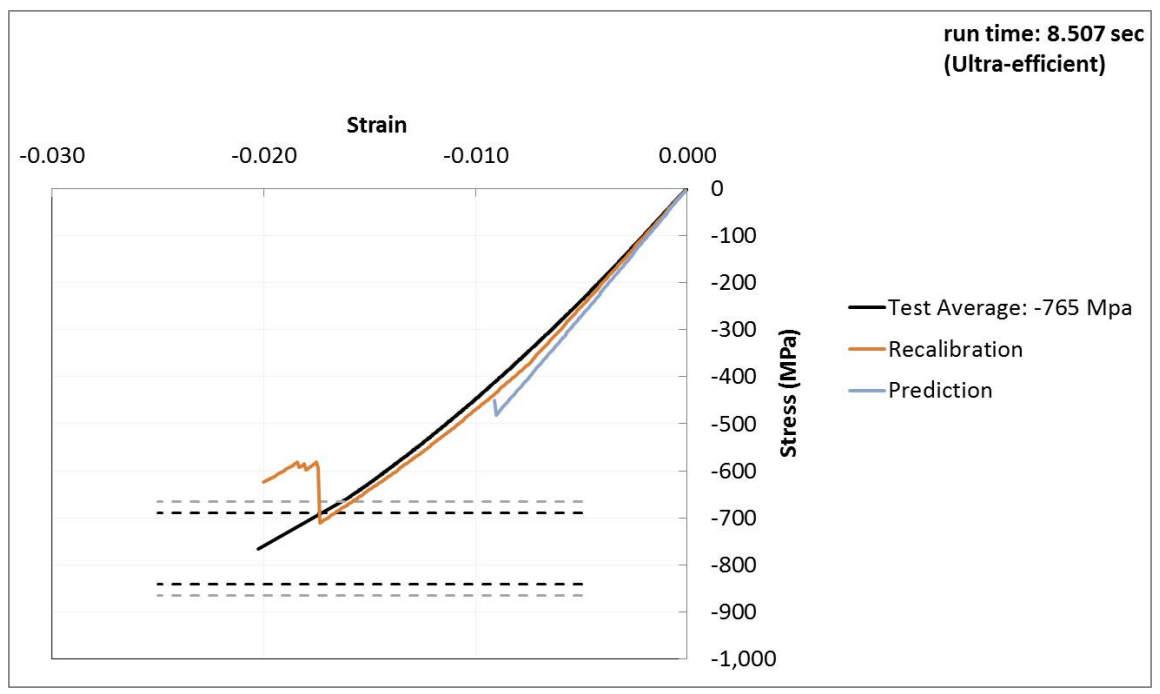

Figure 10b: Stress-Strain prediction and recalibration for the [60/0/-60]3s unnotched layup (Compression) 


\subsubsection{A) Plasticity: Predictions}

The calibrated properties (Table 2) were used in conjunction with the plasticity theory within FEAMAC to predict the failure response of the un-notched multidirectional laminates. Prediction results are presented in Figure 11 . The experimentally reported stress/strain curve for the $[+60 / 0 /-60]_{3 s}$ laminate under tension was predicted successfully with $2.82 \%$ error in ultimate strength prediction. However, the stiffness was over-predicted by approximately $14 \%$. Similar to the predictions with MMCDM, under compression, the strength was under-predicted by $39 \%$, while the stiffness is over-predicted by $14 \%$, majorly due to the assumed low value for the $0^{\circ}$ compression strength.

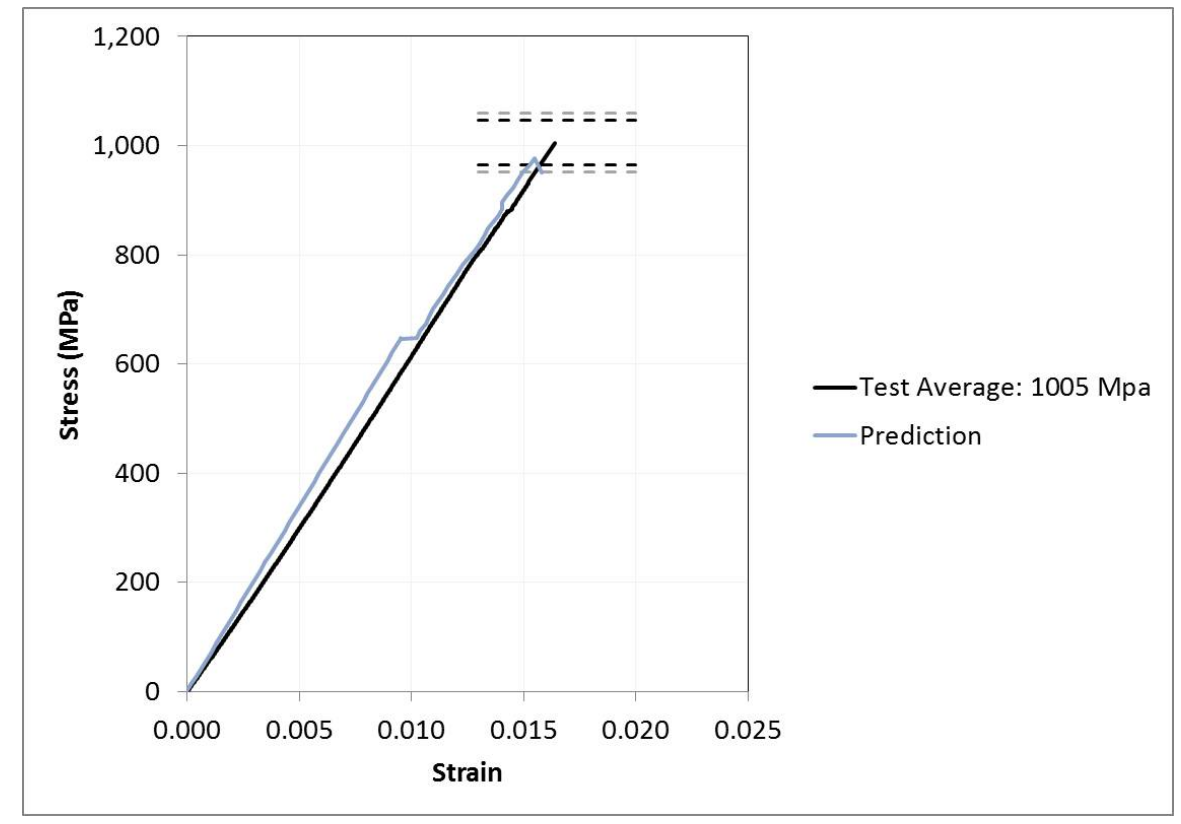

Figure 11a: Stress-Strain prediction for the [60/0/-60]3s unnotched layup (Tension)

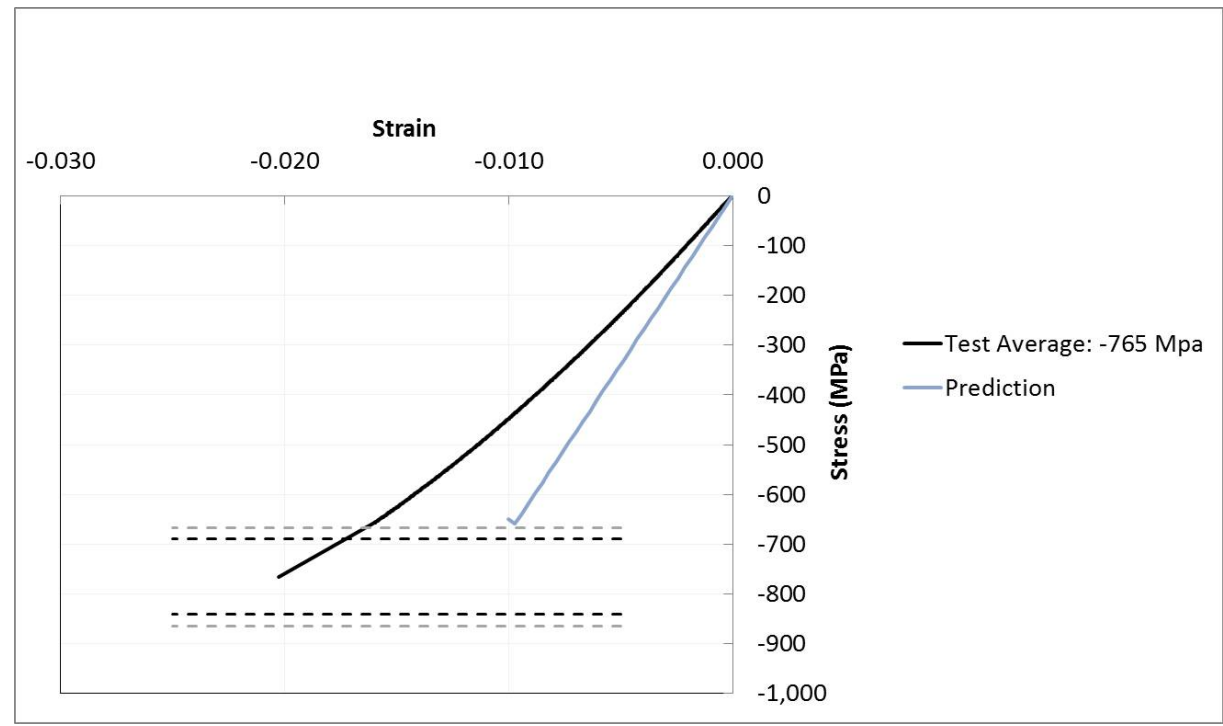

Figure 11b: Stress-Strain prediction for the [60/0/-60]3s unnotched layup (Compression) 


\subsubsection{B) Plasticity: Recalibration}

To improve the results, the fiber volume fraction was set closer to the lower bound of the provided data. Additionally, as with the GMC/MMCDM model, the fiber's longitudinal modulus for tension was lowered to $256 \mathrm{GPa}$ to match the ASTM standard recommendations for the computation of the composite's longitudinal stiffness [11]. Since a significantly lower compressive modulus can be observed in the test data, the compressive modulus was decreased to the same value used in the GMC/MMCDM model (215 GPa) in order to account for the waviness of the fiber, which could be the reason for the lower modulus. Also similar to MMCDM recalibrations, the compressive strength of the fiber was increased to match the recommended value in the literature [11] (see Table 4). The ultimate tensile matrix strain was also increased. Modifications are shown in Table 4 (red), and results are summarized in Figure 12. These changes significantly improved the results of every test case. The stiffnesses are in better agreement with observation and the predicted strengths of the unnotched test cases are still within the confidence bounds.

\begin{tabular}{|l|l|}
\hline $\mathrm{E}_{\mathrm{f} 11}=256 \mathrm{GPa}$ (Tension)/215 GPa (Compression) & $\varepsilon^{\text {ult }}$ fiber (tension) $=0.0161$ \\
\hline $\mathrm{E}_{\mathrm{f} 22}=15 \mathrm{GPa}$ & $\varepsilon^{\text {ult }}$ fiber (compression) $=0.0129$ \\
\hline $\mathrm{V}_{\mathrm{f} 12}=0.28$ & $\mathrm{~V}_{\mathrm{f}}=62 \%$ \\
\hline $\mathrm{V}_{\mathrm{f} 23}=0.19$ & $\varepsilon^{\text {ult }}{ }_{\mathrm{m}}=0.05$ \\
\hline$G_{\mathrm{f} 12}=15 \mathrm{GPa}$ & $\gamma^{\text {ult }}{ }_{\mathrm{m}}=0.06$ \\
\hline $\mathrm{E}_{\mathrm{m}}=3.2 \mathrm{GPa}$ & \\
\hline $\mathrm{V}_{\mathrm{m}}=0.38$ & \\
\hline
\end{tabular}

Table 4: Constituent (fiber/matrix) properties and Plasticity parameters (recalibration)

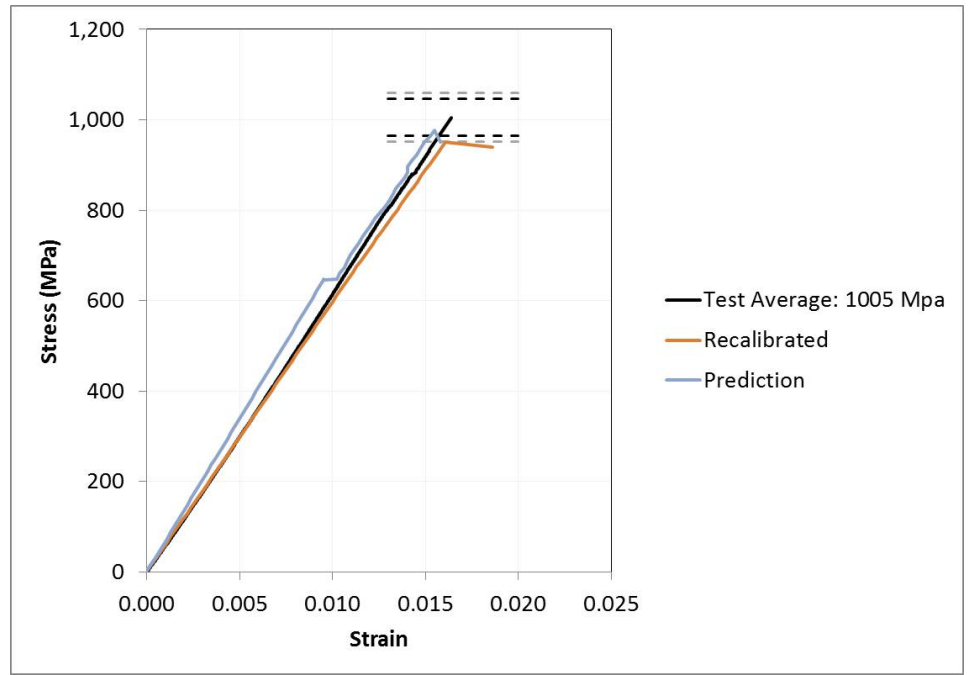

Figure 12a: Stress-Strain prediction and recalibration for the [60/0/-60]3s unnotched layup (Tension) 


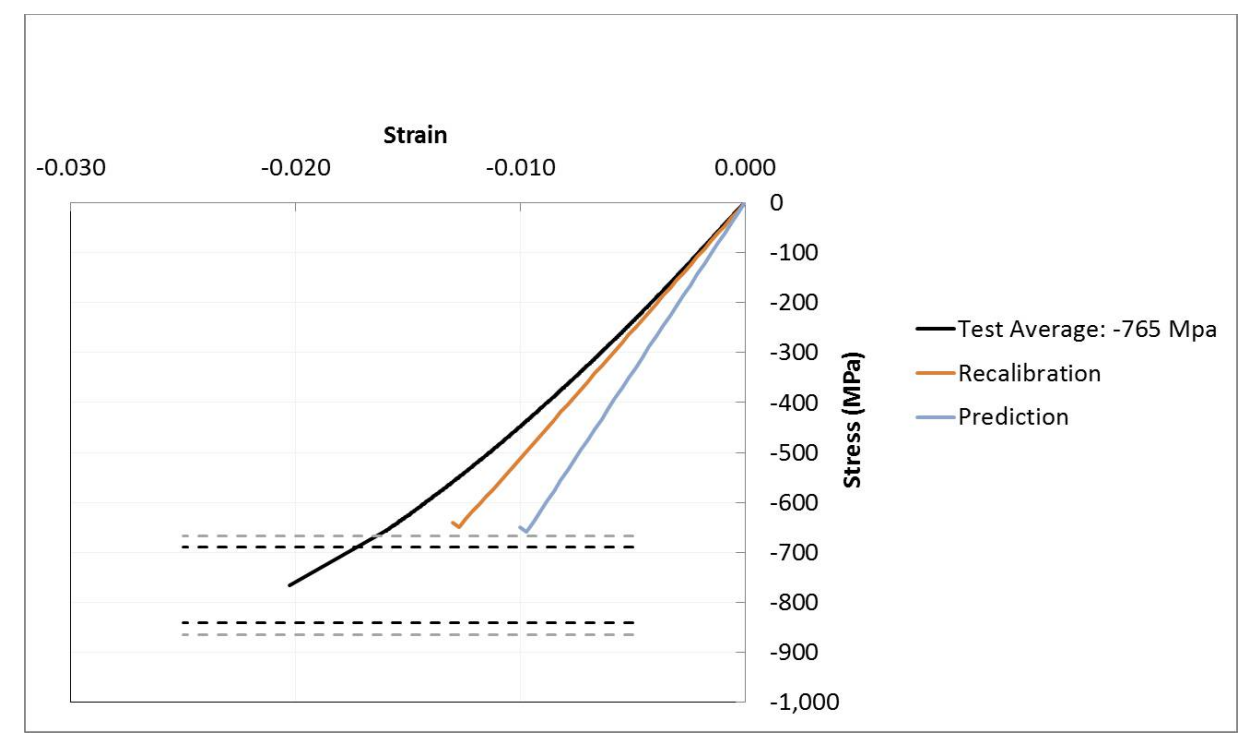

Figure $12 \mathrm{~b}$ : Stress-Strain prediction and recalibration for the [60/0/-60]3s unnotched layup (Compression)

\subsubsection{Summary of Un-notched Analyses}

The summary of static failure predictions and recalibrations for three different unnotched multidirectional layups (including [+60/0/-60 $]_{35}$ ) utilizing MMCDM theory within MAC/GMC (microscale) and plasticity within FEAMAC (multiscale) is given in Table 5. Briefly looking at the results, we can see that both methods presented a good capability in predicting the tensile stiffness of all three layups with maximum of $15.5 \%$ error, which was improved during recalibration. The relative error for tensile strength predictions varied from $1.99 \%$ to $72 \%$ (for layup 3), due to the initially assumed low matrix failure strain, which was also corrected during recalibration. A similar trend was observed for the strain to failure predictions as well. For compression the observed error in stiffness prediction was higher than in tension (40.4\%), due to initial assumptions of compressive stiffness and ultimate strain values. During recalibration, significant improvements were made for all layups under compression.

\begin{tabular}{|l|c|cc|cc|cc|cc|}
\hline \multicolumn{1}{|c|}{ Layups } & \multicolumn{2}{|c|}{$\begin{array}{c}\mathbf{E} \\
(\mathbf{G P a})\end{array}$} & \multicolumn{2}{|c|}{$\begin{array}{c}\text { Plasticity } \\
\text { prediction }\end{array}$} & \multicolumn{2}{c|}{$\begin{array}{c}\text { MMCDM } \\
\text { prediction }\end{array}$} & \multicolumn{2}{c|}{$\begin{array}{c}\text { Plasticity } \\
\text { recalibration }\end{array}$} & \multicolumn{2}{c|}{$\begin{array}{c}\text { MMCDM } \\
\text { recalibration }\end{array}$} \\
\hline Layup 1 (T) & 60.5 & 67.7 & $*(11.91 \%)$ & 67.5 & $(11.53 \%)$ & 59.6 & $-(1.47 \%)$ & 63.2 & $(4.45 \%)$ \\
\hline Layup 2 (T) & 59.5 & 67.8 & $(13.97 \%)$ & 67.5 & $(13.37 \%)$ & 59.7 & $(0.32 \%)$ & 63.2 & $(6.17 \%)$ \\
\hline Layup 3 (T) & 38.0 & 43.9 & $(15.50 \%)$ & 42.0 & $(10.36 \%)$ & 38.9 & $(2.24 \%)$ & 39.5 & $(3.76 \%)$ \\
\hline Layup 1(C) & 48.0 & 67.4 & $(40.48 \%)$ & 54.3 & $(13.24 \%)$ & 50.9 & $(6.13 \%)$ & 50.3 & $(4.79 \%)$ \\
\hline Layup 2 (C) & 48.9 & 67.8 & $(38.74 \%)$ & 54.3 & $(11.14 \%)$ & 51.2 & $(4.77 \%)$ & 50.3 & $(2.84 \%)$ \\
\hline Layup 3 (C) & 33.5 & 42.9 & $(28.07 \%)$ & 34.5 & $(3.07 \%)$ & 33.3 & $-(0.55 \%)$ & 34.5 & $(3.02 \%)$ \\
\hline
\end{tabular}

Table 5a: Stiffness data for three different Layups (unnotched) including Layup 2: $[+60,0,-60]_{35}$ 


\begin{tabular}{|l|c|cc|cc|cc|cc|}
\hline \multicolumn{1}{|c|}{ Layups } & $\begin{array}{c}\boldsymbol{\sigma}_{\max } \\
\text { (MPa) }\end{array}$ & \multicolumn{2}{|c|}{$\begin{array}{c}\text { FEAMAC } \\
\text { prediction }\end{array}$} & \multicolumn{2}{c|}{$\begin{array}{c}\text { GMC } \\
\text { prediction }\end{array}$} & \multicolumn{2}{c|}{$\begin{array}{c}\text { FEAMAC } \\
\text { recalibration }\end{array}$} & \multicolumn{2}{c|}{$\begin{array}{c}\text { GMC } \\
\text { recalibration }\end{array}$} \\
\hline Layup 1 (T) & 866 & 691 & $-(20.2 \%)$ & 1033 & $(19.25 \%)$ & 897.0 & $(3.58 \%)$ & 957 & $(10.46 \%)$ \\
\hline Layup 2 (T) & 1005 & 977 & $-(2.82 \%)$ & 1025 & $(1.99 \%)$ & 951.0 & $-(5.40 \%)$ & 954 & $-(5.13 \%)$ \\
\hline Layup 3 (T) & 473 & 131 & $-(72.3 \%)$ & 789 & $(66.76 \%)$ & 474.0 & $(0.18 \%)$ & 471 & $-(0.41 \%)$ \\
\hline Layup 1 (C) & 603 & 562.0 & $-(6.8 \%)$ & 483 & $-(19.95 \%)$ & 584.0 & $-(3.15 \%)$ & 621 & $(3.00 \%)$ \\
\hline Layup 2 (C) & 765 & 659.0 & $-(13.9 \%)$ & 483 & $-(36.97 \%)$ & 649.0 & $-(15.2 \%)$ & 711 & $-(7.16 \%)$ \\
\hline Layup 3 (C) & 382 & 260.0 & $-(31.9 \%)$ & 446 & $(16.76 \%)$ & 351.0 & $-(8.12 \%)$ & 398 & $(4.22 \%)$ \\
\hline
\end{tabular}

Table 5b: Strength data for three different Layups (unnotched) including Layup 2: $[+60,0,-60]_{35}$

\begin{tabular}{|l|c|cc|cc|cc|cc|}
\hline \multicolumn{1}{|c|}{ Layups } & \multicolumn{2}{|c|}{$\boldsymbol{\varepsilon}_{\max }$} & \multicolumn{2}{|c|}{$\begin{array}{c}\text { FEAMAC } \\
\text { prediction }\end{array}$} & \multicolumn{2}{c|}{$\begin{array}{c}\text { GMC } \\
\text { prediction }\end{array}$} & \multicolumn{2}{c|}{$\begin{array}{c}\text { FEAMAC } \\
\text { recalibration }\end{array}$} & \multicolumn{2}{c|}{$\begin{array}{c}\text { GMC } \\
\text { recalibration }\end{array}$} \\
\hline Layup 1 (T) & 0.014 & 0.013 & $-(7.1 \%)$ & 0.017 & $(21.4 \%)$ & 0.015 & $(7.1 \%)$ & 0.017 & $(21.4 \%)$ \\
\hline Layup 2 (T) & 0.015 & 0.015 & $(0.1 \%)$ & 0.017 & $(13.3 \%)$ & 0.016 & $(6.6 \%)$ & 0.016 & $(13.3 \%)$ \\
\hline Layup 3 (T) & 0.013 & 0.003 & $-(76.9 \%)$ & 0.022 & $(69.2 \%)$ & 0.012 & $-(7.6 \%)$ & 0.013 & $(0.1 \%)$ \\
\hline Layup 1 (C) & 0.014 & 0.008 & $-(42.8 \%)$ & 0.009 & $-(35.7 \%)$ & 0.012 & $-(14.2 \%)$ & 0.014 & $(0.1 \%)$ \\
\hline Layup 2 (C) & 0.021 & 0.009 & $-(57.1 \%)$ & 0.009 & $-(57.1 \%)$ & 0.012 & $-(42.8 \%)$ & 0.017 & $-(19 \%)$ \\
\hline Layup 3 (C) & 0.012 & 0.007 & $-(41.6 \%)$ & 0.013 & $(8.3 \%)$ & 0.011 & $-(8.3 \%)$ & 0.012 & $(0.1 \%)$ \\
\hline
\end{tabular}

Table 5c: Failure strain data for three different Layups (unnotched) including Layup 2: $[+60,0,-60]_{35}$

Although the plasticity model was used in multiscale FEAMAC analyses, it was calibrated using only the "single point" MAC/GMC micromechanics analysis. As such, the MMCDM and plasticity characterization results are nearly identical. However, discrepancy between the GMC/MMCDM and FEAMAC/plasticity coupon models is expected. With MAC/GMC, the entire laminate is modeled as a single point, assuming a homogenous stress state within. In the FEAMAC models, there is a difference in the fiber volume fraction in the gage section and near the gripped edges of the laminate leading to stress concentrations at the transition region. Thus, there are stress gradients in the FEAMAC model.

Moreover, localization within the FEAMAC model leads to mesh dependence when the subcell elimination method is used $[13,14]$, whereas this is alleviated with MMCDM. Additionally, when subcell elimination method is utilized for the fibers in standalone MAC/GMC, there is no length scale dependence because there is no finite dimensionality (infinitely long) associated with the $x_{1}$ direction in the doubly-periodic formulation of GMC. Conversely, once GMC is embedded within the FEM, via FEAMAC, a finite length is immediately linked to the $x_{1}$ direction at the microscale and using the subcell elimination method for the fiber also becomes pathologically mesh dependent. In reality, localization within the composite occurs due to pre-existing flaws (resulting from manufacturing and processing) in the material. It is difficult to characterize these flaws. As such, modeling flawed coupon laminates with FEM is challenging. 


\subsection{Notched Laminate}

Since a notched laminate is composed of a complex geometry that cannot be modeled with MAC/GMC alone, the FEAMAC multiscale framework was utilized, in conjunction with plastic theory and the subcell elimination method, to model the response of the notched coupons. The same element types and modeling strategies, described in section 3.2 for un-notched laminates, were employed except the uniform fiber volume fraction is used throughout the coupons as the notch provides a sufficient stress concentration. Figure 13 shows different meshes used to analyze this layup under tension and compression (tabs are excluded).

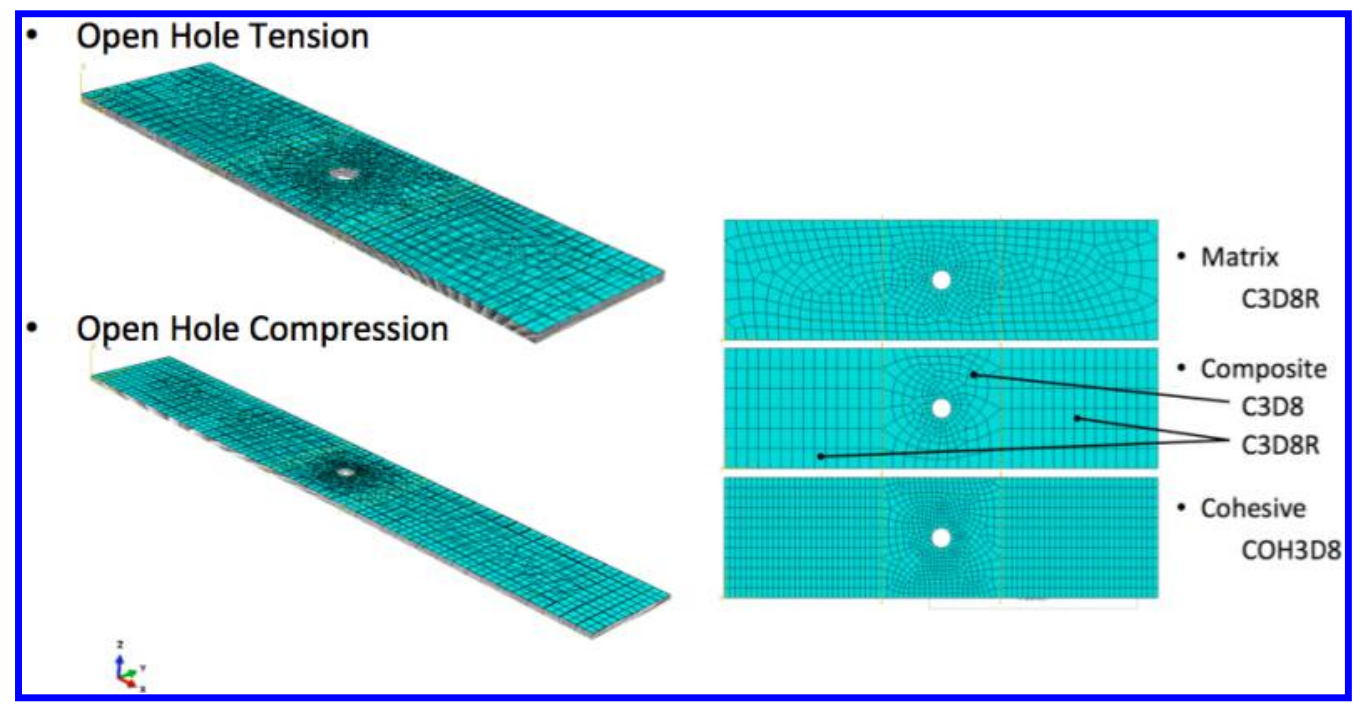

Figure 13: Finite element meshes used to analyze the $[+60 / 0 /-60]_{3 s}$ layup (notched)

\subsubsection{FEAMAC Prediction: Plasticity}

Using the aforementioned FE model description, the constituent properties calibrated for the plasticity theory (Table 2) were used in FEAMAC to predict the failure response of the notched $[+60 / 0 /-60]_{3 s}$ multidirectional specimens. The blind prediction (stress/strain curve) for this layup is compared to reported experiments in Figure 14. The stiffness prediction matched the experimental result very well with an over prediction of $5 \%$. The tensile strength is under predicted by $26.3 \%$, which is probably related to the assumed low matrix failure strain, or the mesh density around the notch. Unfortunately, mesh dependency of the subcell elimination method within FEAMAC is a disadvantage at this point, and further mesh studies might be required to achieve optimum results. Similar to the unnotched laminates, compressive stiffness is over predicted by $23 \%$ and compressive strength is under predicted by $15 \%$ due to the initially-assumed high compressive fiber modulus and a low compressive fiber strength. 


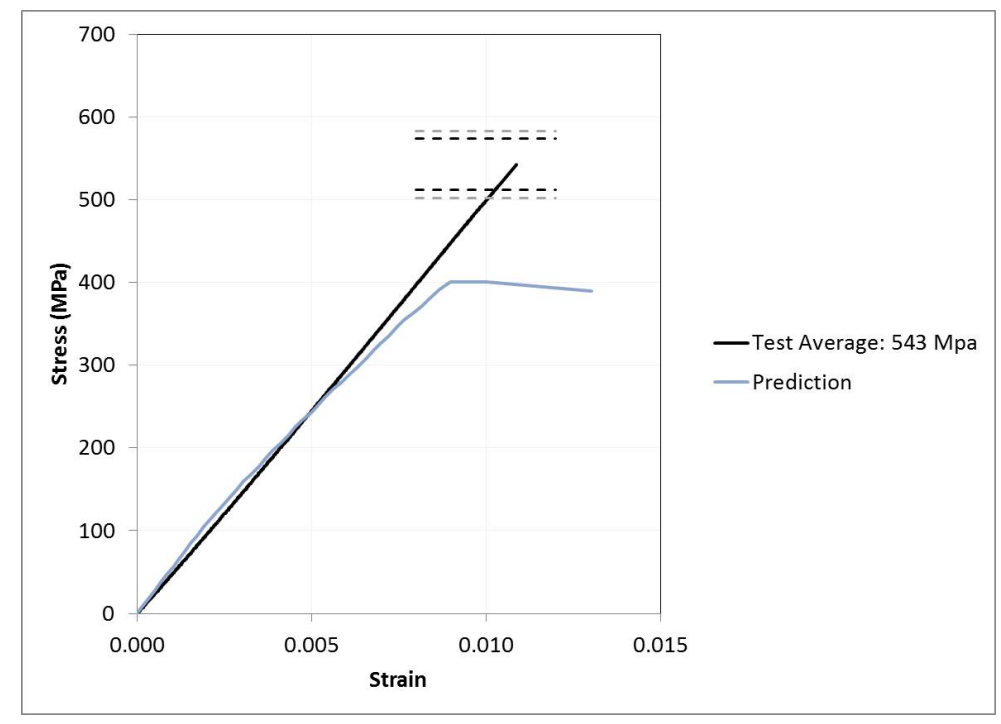

Figure 14a: Stress-Strain prediction and recalibration for the [60/0/-60]3s notched layup (Tension)

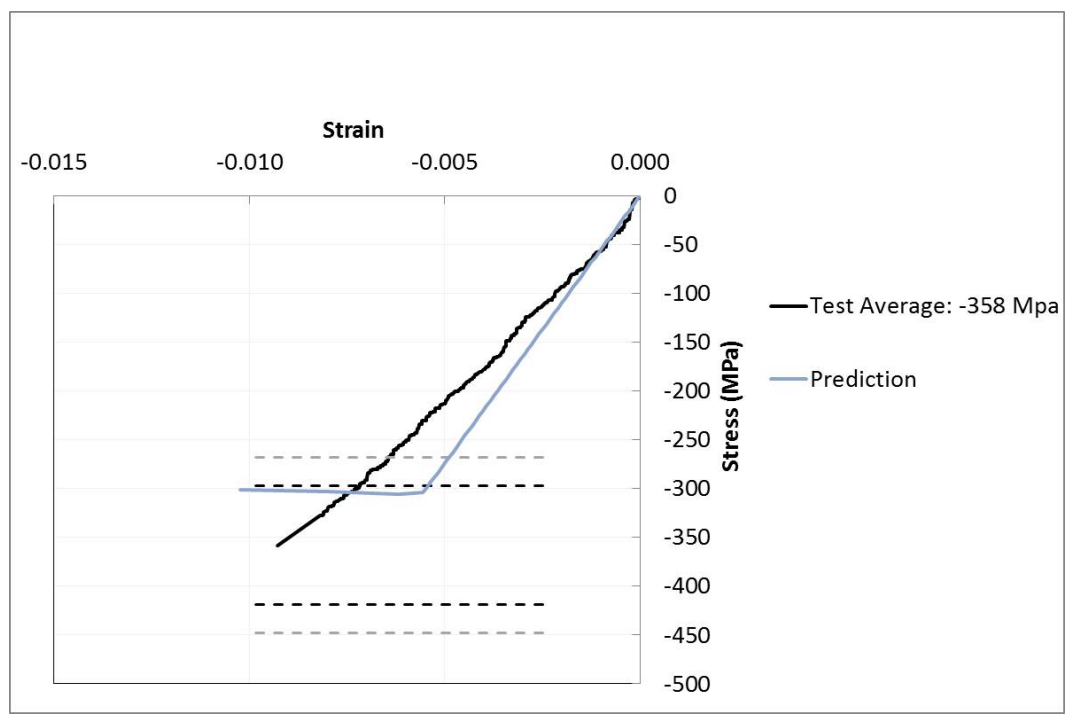

Figure 14b: Stress-Strain prediction and recalibration for the [60/0/-60]3s notched layup (Compression)

\subsubsection{FEAMAC Recalibration: Plasticity}

The same recalibrated properties obtained for the un-notched laminate modeled with plasticity (Section 4.1.2 B-Table 4) were used for the recalibration phase corresponding to the notched laminates. Results are shown in Figure 15 . With the applied modifications the tensile strength prediction was improved, however, the strength value is still lower than the given confidence bound. This might be due to the assumed mesh density around the notch or the matrix failure criterion. The compressive strength and stiffness predictions were greatly improved and a very good agreement was achieved with the experiments ( 11 and $55 \%$ error respectively). 


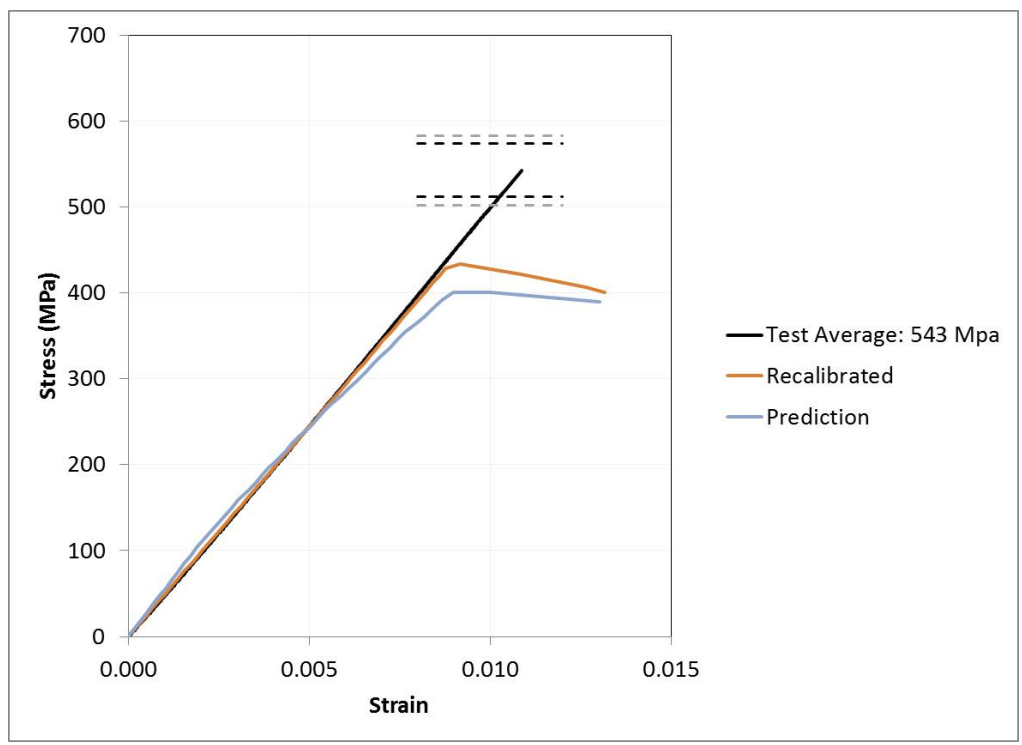

Figure 15a: Stress-Strain prediction and recalibration for the [60/0/-60]3s notched layup (Tension)

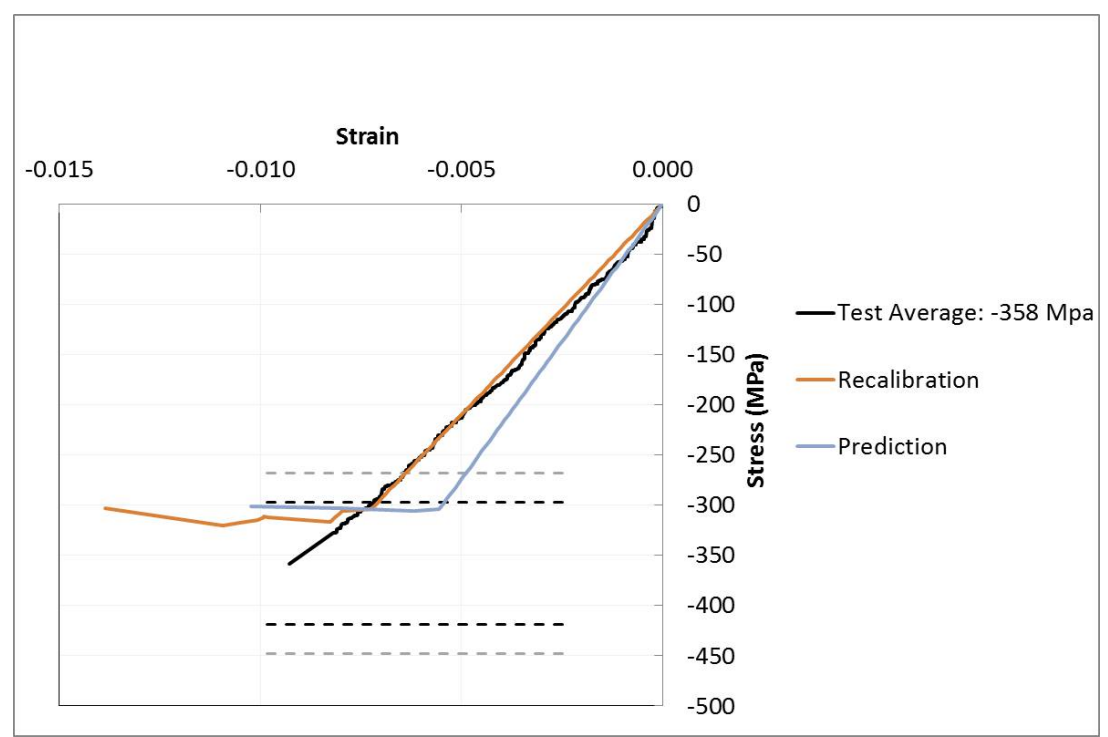

Figure 15b: Stress-Strain prediction and recalibration for the [60/0/-60]3s notched layup (Compression)

Figure 16 shows the contour plots of the individual plies (a measure of "damage", i.e. second invariant (J2) of inelastic strain, see Fig. 16a) and the individual interface degradations for this laminate at $90 \%$ failure. The $\mathrm{J} 2$ measure around the notch shows a progressive growth together with the delamination initiated approximately in the same elements with a semi-circular growth pattern. 


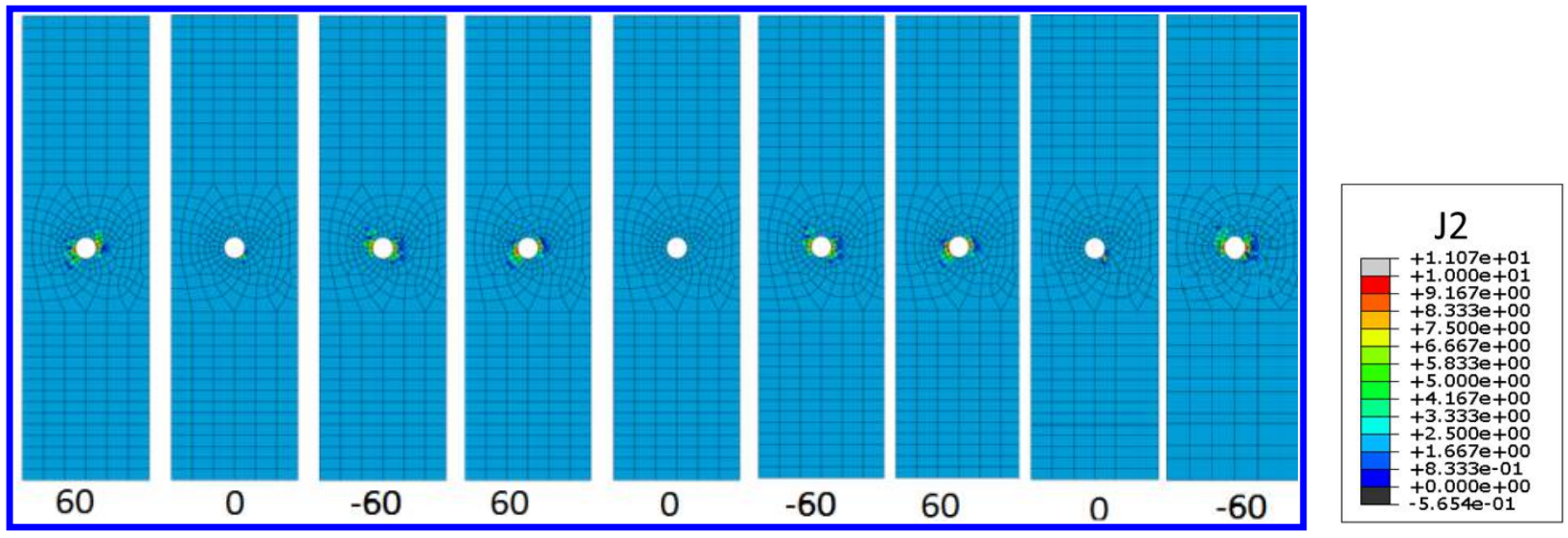

Figure 16a: J2 inelastic strain contour plots of the individual plies
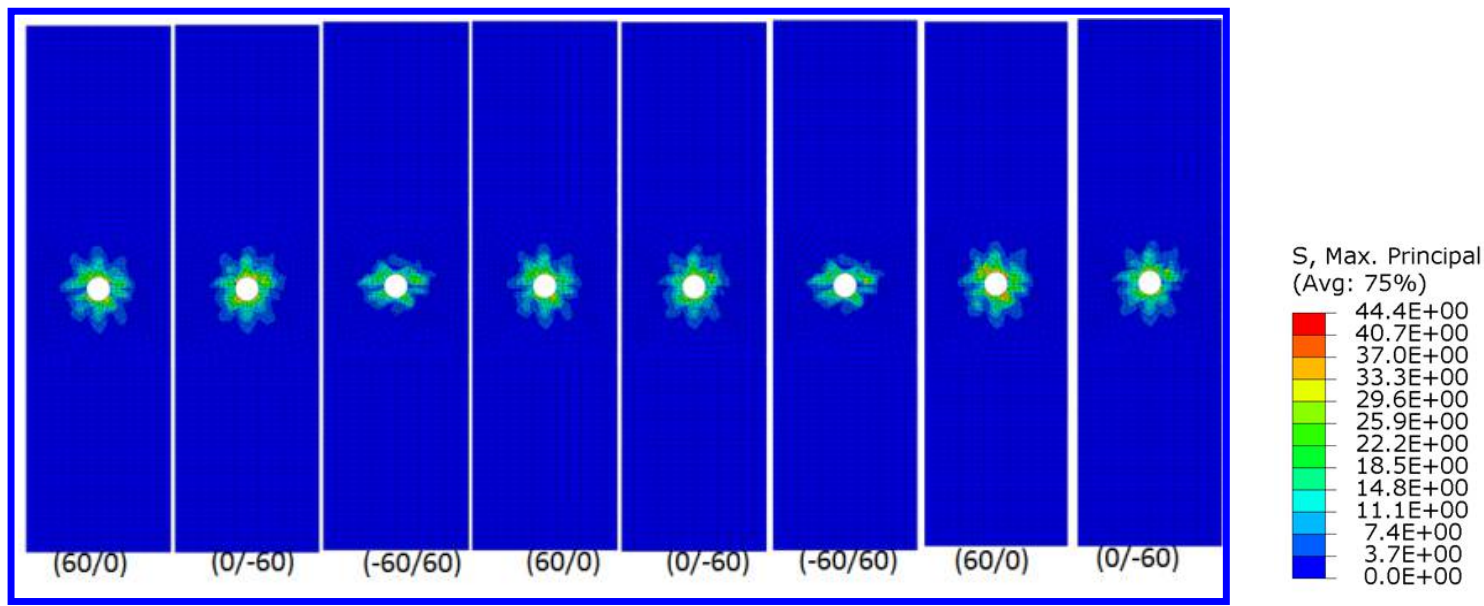

Figure 16b: Contour plots of the individual interface.

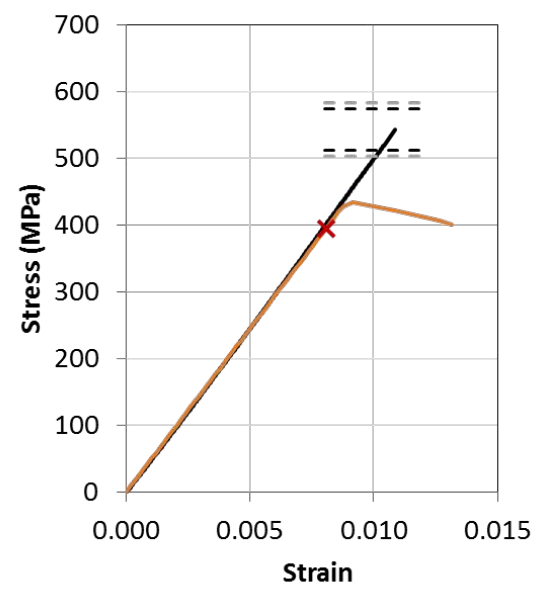

Figure 16c: Stress-strain point at which contour plots were constructed. 


\subsubsection{Summary of Notched Analyses}

The summary of static failure predictions and recalibrations for three different notched multidirectional layups (including [+60/0/-60 $]_{3 s}$ ) utilizing plasticity within FEAMAC (multiscale) is given in Table 6. Briefly looking at the results, we can see that in the case of tension FEAMAC with plasticity provided good capability in predicting the tensile stiffness of all three layups with maximum of $5 \%$ error, which was improved during recalibration. However, despite a $\sim 260 \%$ increase in the critical matrix strength, the ultimate load predictions of the notched coupons only changed by approximately $10 \%$. This indicates that it may be sufficient to model the laminates using only an axial, fiber failure criterion. This is further evidenced by the lack of any matrix subcell failure in the recalibrated predictions prior to fiber failure. Once the compressive strength and modulus of the fiber were adjusted, significant improvements were observed in compressive stiffness and strength predictions for all three layups.

\begin{tabular}{|c|c|cc|cc|}
\hline Layups & $\begin{array}{c}\text { E } \\
\text { (GPa) }\end{array}$ & \multicolumn{2}{|c|}{$\begin{array}{c}\text { FEAMAC } \\
\text { prediction }\end{array}$} & \multicolumn{2}{c|}{$\begin{array}{c}\text { Plasticity } \\
\text { recalibration }\end{array}$} \\
\hline Layup 1 (T) & 48.3 & 46.7 & $*(3.3 \%)$ & 49.1 & $(1.6 \%)$ \\
\hline Layup 2 (T) & 48.8 & 51.1 & $(4.7 \%)$ & 48.9 & $(0.2 \%)$ \\
\hline Layup 3 (T) & 32.4 & 33.5 & $(3.3 \%)$ & 33.6 & $(3.7 \%)$ \\
\hline Layup 1 (C) & 44.5 & 54.3 & $(22 \%)$ & 41.6 & $-(6.5 \%)$ \\
\hline Layup 2 (C) & 44.4 & 54.8 & $(23 \%)$ & 41.9 & $-(5.6 \%)$ \\
\hline Layup 3 (C) & 30.1 & 37.4 & $(25 \%)$ & 29.1 & $-(3.3 \%)$ \\
\hline
\end{tabular}

\begin{tabular}{|c|c|cc|cc|}
\hline Layups & \multirow{2}{*}{$\boldsymbol{\sigma}_{\max }$ (MPa) } & \multicolumn{2}{c|}{$\begin{array}{c}\text { FEAMAC } \\
\text { prediction }\end{array}$} & \multicolumn{2}{c|}{$\begin{array}{c}\text { FEAMAC } \\
\text { recalibration }\end{array}$} \\
\cline { 1 - 4 } Layup 1 (T) & 554 & 329 & $-(40.6 \%)$ & 464 & $-(16.2 \%)$ \\
\hline Layup 2 (T) & 543 & 400 & $-(26.3 \%)$ & 433 & $-(20 \%)$ \\
\hline Layup 3 (T) & 409 & 111 & $-(72.8 \%)$ & 378 & $-(7.5 \%)$ \\
\hline Layup 1 (C) & 341 & 294 & $-(13.7 \%)$ & 367 & $(7.6) \%$ \\
\cline { 1 - 3 } Layup 2 (C) & 358 & 305 & $-(14.8 \%)$ & 320 & $-(10.6 \%)$ \\
\cline { 1 - 4 } Layup 3 (C) & 295 & 263 & $-(11.0 \%)$ & 329 & $(11.5 \%)$ \\
\hline
\end{tabular}

\begin{tabular}{|c|c|cc|cc|}
\hline Layups & $\boldsymbol{\varepsilon}_{\max }$ & \multicolumn{2}{c|}{$\begin{array}{c}\text { FEAMAC } \\
\text { prediction }\end{array}$} & \multicolumn{2}{c|}{$\begin{array}{c}\text { FEAMAC } \\
\text { recalibration }\end{array}$} \\
\cline { 1 - 5 } Layup 1 (T) & 0.0125 & 0.011 & $-(12 \%)$ & 0.01 & $-(20 \%)$ \\
\hline Layup 2 (T) & 0.011 & 0.008 & $-(27 \%)$ & 0.008 & $-(27 \%)$ \\
\hline Layup 3 (T) & 0.014 & 0.006 & $-(57 \%)$ & 0.012 & $-(14 \%)$ \\
\hline Layup 1 (C) & 0.0075 & 0.004 & $-(46 \%)$ & 0.008 & $-(6 \%)$ \\
\hline Layup 2 (C) & 0.009 & 0.006 & $-(33 \%)$ & 0.008 & $-(11 \%)$ \\
\hline Layup 3 (C) & 0.01 & 0.007 & $-(30 \%)$ & 0.011 & $-(10 \%)$ \\
\hline
\end{tabular}

Table 6: Stiffness, strength, and maximum strain data for three different Layups including Layup 2:

$[+60,0,-60]_{3 s}$ (T:Tension, C:Compression, *Error, Layup 1: $[0,45,90,-45]_{2 s}$ Layup 2: $[+60,0,-60]_{3 S}$ Layup 3 : $[+30,+60,90,-60,-30]_{2 S}$ 


\subsection{Conclusion}

MMCDM model standalone MAC/GMC and plasticity within the FEAMAC multiscale framework were successfully employed to simulate tensile and compressive failure of an unnotched multidirectional IM7/977-3 composite layup ([+60/0/-60 $\left.]_{35}\right)$. Under tension, the ultimate strength for this particular laminate was successfully reproduced with minimal error. However, the stiffness was over-predicted in both methods. Under compression, the strength was under-predicted, while the stiffness was overpredicted due to the assumed low value for the $0^{\circ}$ compression strength. Minor modifications were made to improve the observed discrepancies in both methods, and the stress/strain response of the laminate was significantly improved. Using the same modifications for the unnotched layup (modeled through plasticity theory) the tension and compression response for the notched laminate was significantly improved as well. In order to address mesh dependency of the current approach, MMCDM (a meshobjective tool) is planned to be employed within FEAMAC, with an energetically consistent handshaking method, to predict the failure of this laminate for future studies.

This study has demonstrated MAC/GMC to be viable tool for the prediction of the strength of laminates. The computational efficiency (run times on the order of seconds using one CPU) of the method affords designers the opportunity to enact incredibly thorough trade studies. Moreover, once the constituent parameters have been calibrated sufficiently, it appears (through this demonstration) that GMC provides the correct trends and holds predictive potential. Unfortunately, GMC alone is not robust enough to incorporate structural features such as notches or holes. For this, however, the FEAMAC multiscale framework is available at an added computational cost.

Moreover, this exercise has revealed that, as multiscale models become more popular within the research community, a paradigm shift in test methods is required to facilitate their use in industry. The coupon level experiments used to characterize/calibrate the constituent-level constitutive models should serve as validation data for the micromechanics or multiscale models. In order to truly evaluate the predictive capability of mico/multiscale models, constituent data must be provided and the coupon behavior should be predicted. Additionally, un-notched, unidirectional coupon experiments may not provide the necessary data needed to characterize sophisticated progressive damage models. Without any dominant flaw, the failure of these coupons depends on the subscale defects which are extremely

difficult to characterize. Furthermore, unidirectional laminates fail prematurely, compared to laminates used in service, because there are no plies to constrain matrix cracks (allowing for multiple cracks) or provide fiber-bridging support (resulting in toughening). Thus, the failure mechanisms observed in unidirectional laminates (used to characterize the models) and in multi-angle laminates (used in service) are fundamentally different.

\section{Acknowledgement}

Authors B. Stier, L. Hansen, and A.M. Waas would like to acknowledge funding by Lockheed Martin under AFRL Tech Scout 1: Damage Tolerant Design Principles (DTDP) program, Dr. Steve Engelstad, Principle Investigator Lockheed Martin. Dr. Stephen B. Clay, AFRL, program manager.

\section{References:}

1. Bogetti, T.A., Hoppel, C.P.R., Harik, V.M., Newill J.F, Burns, B.P., "Predicting the Nonlinear Response and Failure of Composite Laminates: Correlation with Experimental Results," Composites Science and Technology, Vol. 64, Nos.3-4, 2004, pp.4

-2. Paley, M. Aboudi, J., "Micromechanical Analysis of Composites by the Generalized Cells Model, "Mechanics of Materials, Vol.14, 1992, pp.127-139. 
3. Aboudi, J., Arnold, S.M., Bednarcyk, B.A., Micromechanics of Composite Materials: A Generalized Multiscale Analysis Approach, Elsevier, Inc., 2013.

4. Bednarcyk, B.A., Aboudi, J., Arnold, S.M., "Micromechanics modeling of composites subjected to multiaxial progressive damage in the constituents, "AIAA J., Vol. 48, 2010, pp.1367-1378.

5. Pineda, E.J., Bednarcyk, B.A., Arnold, S.M., "Achieving ICME with Multiscale Modeling: The Effects of Constituent Properties and Processing on the Performance of Laminated Polymer Matrix Composite Structures", AIAA SciTech, 2014, 55th AIAA/ASMe/ASCE/AHS/SC Structures, Structural Dynamics, and Materials Conference.

6. Sicking, D. L. "Mechanical characterization of nonlinear laminated composites with transverse crack growth", 1992, Ph.D. thesis, Texas A\&M University, College Station, TX.

7. Schapery, R. A., and D. L. Sicking. "A theory of mechanical behavior of elastic media with growing damage and other changes in structure", 1995, in Mechanical Behavior of Materials, edited by A. Bakker, pp. 45-76, Delft University Press, Delft, The Netherlands.

8. Lamborn, M. J., and R. A. Schapery. "An investigation of deformation path-independence of mechanical work in fiber-reinforced plastics", 1988, in Proceedings of the Fourth Japan-U.S. Conference on Composite Materials, Technomic Publishing Co., Inc., Lancaster, PA.

9. Wilt, T. E. "On the finite element implementation of the generalized method of cells micromechanics constitutive model", 1995, NASA/CR-1995-195451.

10. Bednarcyk, B. A., and S. M. Arnold. "A framework for performing multiscale stochastic progressive failure analysis of composite structures, 2006, in Proceedings of the 2006 ABAQUS User's Conference.

11. Experimental results and notes provided by Steve Clay, AFRL under the Tech Scout 1 program.

12. Dassault Systèmes Simulia Corp. (2011): Abaqus User's Manual, Vol. 1-3, Version 6.11-1. Dassault Systèmes Simulia Corp., Providence, RI, 2011.

13. Pineda, E. J., Bednarcyk, B. A., Waas, A. M., Arnold, S. M. "Progressive failure of a unidirectional fiberreinforced composite using the method of cells", 2013, Discretization objective computational results. Int. J. Solids Struct., vol. 50, no. 9, pp. 1203-1216.

14. Pineda, E. J., Bednarcyk, B. A., Waas, A. M., and Arnold, S. M. "On multiscale modeling using the generalized method of cells: Preserving energy dissipation across disparate length scales," ,2013, CMC-Comput. Mater. Con. 25(2), 119-154. 